\title{
Non-linear dynamics of cardiac alternans: subcellular to tissue-level mechanisms of arrhythmia
}

\author{
Stephen A. Gaeta and David J. Christini* \\ Department of Physiology, Biophysics and Systems Biology, Weill Cornell Medical College, New York, NY, USA
}

\section{Edited by:}

Eric A. Sobie, Mount Sinai School of

Medicine, USA

\section{Reviewed by:}

Richard Gray, Food and Drug

Administration, USA

Thomas O'Hara, Johns Hopkins

University, USA

*Correspondence:

David J. Christini, Greenberg Division of Cardiology, Weill Cornell Medical

College, 1300 York Avenue, New York, NY 10065, USA.

e-mail:dchristi@med.cornell.edu
Cardiac repolarization alternans is a rhythm disturbance of the heart in which rapid stimulation elicits a beat-to-beat alternation in the duration of action potentials and magnitude of intracellular calcium transients in individual cardiac myocytes. Although this phenomenon has been identified as a potential precursor to dangerous reentrant arrhythmias and sudden cardiac death, significant uncertainty remains regarding its mechanism and no clinically practical means of halting its occurrence or progression currently exists. Cardiac alternans has well-characterized tissue, cellular, and subcellular manifestations, the mechanisms and interplay of which are an active area of research.

Keywords: cardiac alternans, calcium handling, subcellular alternans, repolarization alternans, T-wave alternans, pattern formation

\section{INTRODUCTION}

Sudden cardiac death (SCD) is the most catastrophic manifestation of heart disease, responsible for the deaths of an estimated 325,000 Americans annually (Verrier et al., 2009). SCD most commonly occurs as a result of reentrant tachyarrhythmias (ventricular tachycardia (VT) and ventricular fibrillation (VF); Zipes and Jalife, 2004), but reliable identification of those patients at highest risk for these events has proven a difficult clinical challenge. Recently, an electrocardiogram (ECG) abnormality, "T-wave alternans" (TWA), has been identified as a sensitive indicator of risk for SCD, thereby becoming the focus of considerable clinical and basic science research (Walker and Rosenbaum, 2003; Narayan, 2008).

T-wave alternans is defined as a beat-to-beat alternation in the shape, amplitude, or timing of the T-wave on the ECG, indicative of an underlying alternation in ventricular repolarization (Figure 1; Narayan, 2008). TWA has been associated clinically (Rosenbaum et al., 1994; Narayan, 2008; Narayan et al., 2011) and experimentally (Chinushi et al., 1998, 2003; Pastore et al., 1999; Shimizu and Antzelevitch, 1999) with the onset of potentially fatal arrhythmias (VT/VF) in a broad range of clinical contexts, and is now established as a sensitive marker of risk for SCD. TWA testing may be useful in risk stratification for prophylactic implantable cardioverter-defibrillator (ICD) use (Narayan, 2008). The clinical utility of TWA is the subject of ongoing clinical research, however, and may be limited in part by methodological difficulties (see Nieminen and Verrier, 2010; Verrier et al., 2011, for example).

TWA on the ECG was recently shown to be a manifestation of an alternation in the duration of consecutive action potentials (APs) of ventricular myocytes (cellular alternans; Pastore et al., 1999). Theoretical and experimental studies have established a putative mechanistic link between this tissue-level alternans and arrhythmogenesis (described below; Chinushi et al., 1998, 2003; Pastore et al., 1999; Shimizu and Antzelevitch, 1999). The underlying mechanism of cellular alternans itself remains unclear, however, and no clinically practical means of halting its formation or progression to SCD currently exists.

As imaging techniques have rapidly progressed, the complex subcellular dynamics of cardiac myocytes and their importance in physiology and disease has been increasingly recognized. Cellular alternans is now thought to result from the interplay of ion channels at the cell surface and the complex dynamics of intracellular calcium cycling that are responsible for the variation in calcium concentration seen with each beat. Most recently, so-called "subcellular alternans" has been frequently reported, in which alternations in the magnitude of intracellular calcium transients are seen to vary spatially within an individual myocyte, such that the calcium transients of adjacent regions of the cell alternate with opposite phase. Although significant uncertainty remains regarding its mechanism, the arrhythmogenic potential of subcellular alternans has already been recognized and has motivated a quickly growing field of its research.

\subsection{RESTITUTION}

The duration of each cardiac action potential is an important determinant of electrical stability and arrhythmogenicity in the heart. Under normal conditions, as stimulus frequency is increased (and the diastolic interval is therefore decreased) the resulting action potentials shorten (Bass, 1975). This "action potential duration (APD) restitution" ensures that the diastolic interval (DI) is preserved even during rapid pacing, thereby allowing adequate filling of the ventricles and perfusion of the coronary system. APD restitution is frequently quantified through the "APD restitution curve," in which the APD of each beat is plotted against the duration of the preceding diastolic interval as the cycle length is decreased (Figure 2A). APD normally decreases monotonically with decreasing diastolic interval (as in Figure 2A), but nonmonotonic relationships have also been reported (Koller et al., 1998; Franz, 2003). As described below, the slope of this curve may be an important determinant of the stability of membrane voltage $\left(\mathrm{V}_{\mathrm{m}}\right)$ dynamics. 


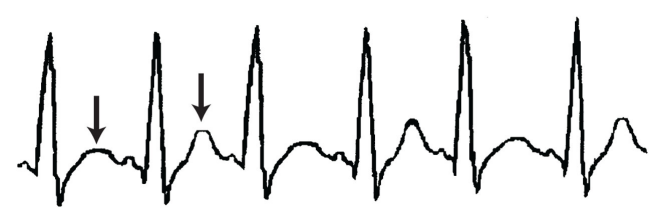

FIGURE 1 | T-wave alternans on the ECG. Large amplitude alternations in the T-wave (arrows) are seen in this example. This TWA is indicative of an underlying alternation in the action potential durations of cardiac myocytes. Adapted from Narayan (2006).

APD restitution is primarily achieved through tight control of the duration of the AP plateau, which is maintained by a delicate balance of several inward and outward currents. The timedependent recovery characteristics of the channels responsible for these currents make the time required for repolarization (and thus the APD) sensitive to changes in the preceding diastolic interval. Specifically, at most cycle lengths restitution is attributed to incomplete recovery from inactivation of L-type $\mathrm{Ca}^{2+}$ channels, with the decreased L-type $\mathrm{Ca}^{2+}$ channel current $\left(\mathrm{I}_{\mathrm{CaL}}\right)$ available following short DIs leading to early repolarization (and a shorter APD). In addition to $\mathrm{I}_{\mathrm{CaL}}$, the slope of the APD restitution curve has been shown theoretically and experimentally to be dependent on the kinetics of several other sarcolemmal currents, including recovery from inactivation of depolarizing sodium channels $\left(\mathrm{I}_{\mathrm{Na}}\right)$ and deactivation of hyperpolarizing potassium channels $\left(\mathrm{I}_{\mathrm{Kr}}\right.$ and $\mathrm{I}_{\mathrm{Ks}}$; Fox et al., 2002a; Shiferaw et al., 2006; O'Hara et al., 2011). The contribution of each of these currents to APD restitution varies with the length of the preceding DI, according to their specific time constants of recovery (Franz, 2003).

The conduction velocity $(\mathrm{CV})$ of action potential propagation in tissue is similarly dependent on the duration of the preceding diastolic interval, due primarily to incomplete recovery from inactivation of the inward sodium channels responsible for the rapid upstroke of the AP (Weiss et al., 2006). Analogous to APD restitution, this "CV-restitution" dictates that APs following short DIs propagate more slowly than those following long DIs.

\section{CARDIAC MYOCYTE CALCIUM CYCLING DYNAMICS}

Each AP in a cardiac myocyte is accompanied by a large, transient rise in cytosolic free calcium concentration $\left(\left[\mathrm{Ca}^{2+}\right]_{i}\right)$ that, in addition to other roles, is responsible for the initiation of contraction. This $\mathrm{Ca}^{2+}$ transient is the product of the coordinated activity of a large number of cellular processes that control the release and reuptake ("cycling") of $\mathrm{Ca}^{2+}$ during each beat, the dynamics of which are known to play important roles in health and disease.

Depending on the species, as much as $90-95 \%$ of the increase in $\mathrm{Ca}^{2+}$ during each $\mathrm{Ca}^{2+}$ transient is released from the sarcoplasmic reticulum (SR), a diffuse intracellular tubular network surrounding the contractile elements of the myocyte (myofibrils) that stores $\mathrm{Ca}^{2+}$ in high concentration (Figure 3; Stern, 1992; Stern et al., 1999). With each AP, the small influx of $\mathrm{Ca}^{2+}$ into the cell through L-type $\mathrm{Ca}^{2+}$ channels (primarily during the AP plateau) activates Ryanodine receptors (RyRs) in the SR membrane to open, thereby releasing a much larger amount of $\mathrm{Ca}^{2+}$ from the SR. This process,

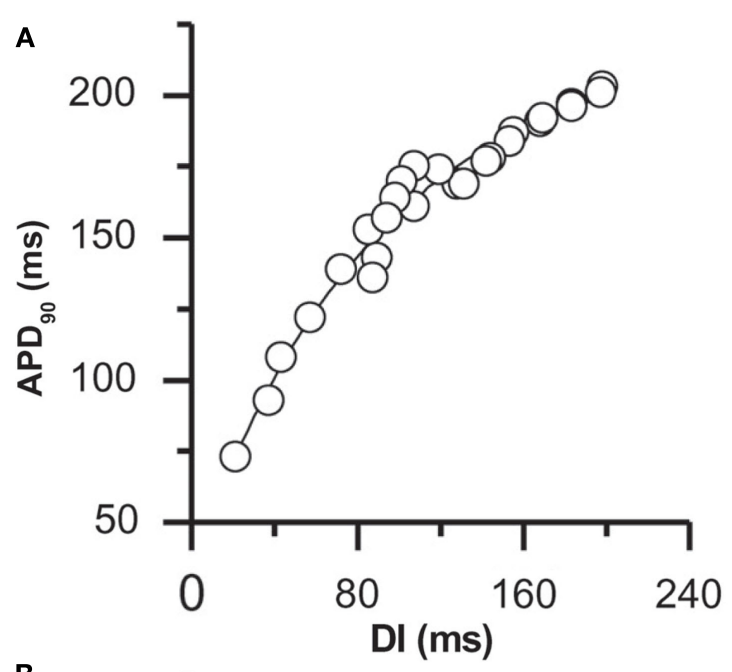

B

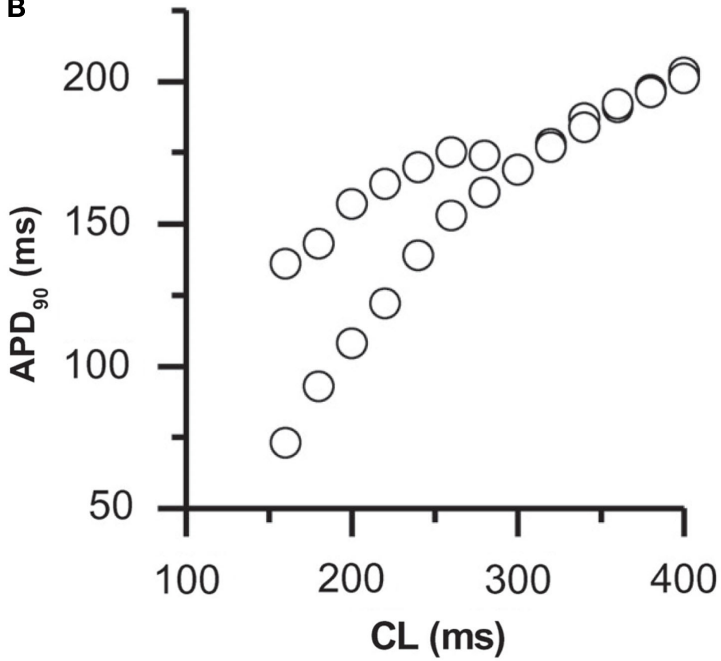

FIGURE 2 |APD restitution in rabbit ventricular myocytes. The rate-dependence of APD is shown by plotting the APD against $(\mathbf{A})$ the duration of the preceding $\mathrm{DI}$ and $(\mathbf{B})$ the cycle length $(C L$; from the same data set). In this myocyte, alternans occurred at a pacing cycle length of $280 \mathrm{~ms}$, corresponding to a DI of $120 \mathrm{~ms}$. The slope of the restitution curve at this DI was 0.56 (from (A)), significantly less than the slope predicted to be necessary if alternans results from APD restitution alone. Adapted from Goldhaber et al. (2005). Note that similar data has been reported in human myocardium (see, for example, Koller et al., 2005).

known as " $\mathrm{Ca}^{2+}$-induced $\mathrm{Ca}^{2+}$ release" (CICR), couples the depolarization of the membrane to the large rise in $\left[\mathrm{Ca}^{2+}\right]_{i}$ necessary to initiate myofilament contraction.

The amplitude of the SR $\mathrm{Ca}^{2+}$ release is a graded function of the magnitude and duration of the triggering $\mathrm{L}$-type $\mathrm{Ca}^{2+}$-channel current. This "graded release" creates a paradox, however - given that approximately $10 \times$ the amount of $\mathrm{Ca}^{2+}$ needed to trigger CICR is released from the SR, one would expect $\mathrm{SR} \mathrm{Ca}^{2+}$ release to trigger further release, thereby creating a regenerative, all-ornone process (Stern, 1992; Stern et al., 1999). The resolution to this paradox was ultimately found in the spatially distributed nature of subcellular $\mathrm{Ca}^{2+}$-cycling dynamics. 


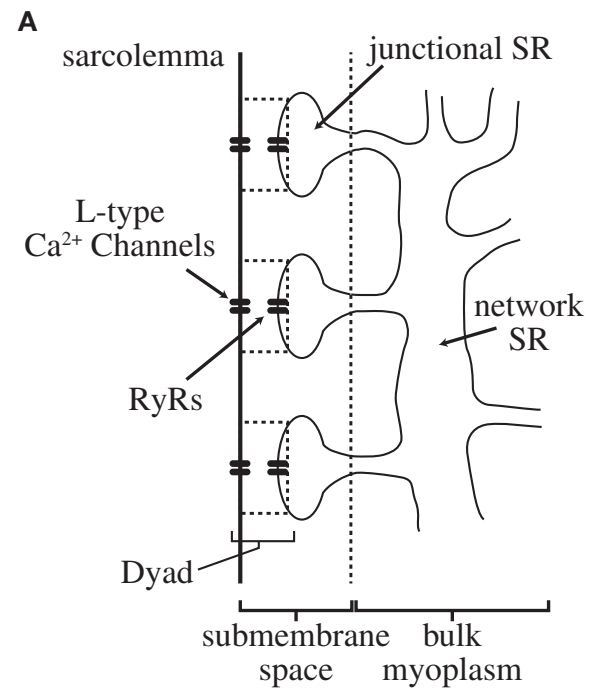

FIGURE 3 | Cardiac myocyte intracellular $\mathrm{Ca}^{2+}$-cycling components. (A) The sarcolemma of a cardiac myocyte forms a series of regularly distributed invaginations (T-tubules) into the interior of the cell (perpendicular to the long axis). The area between each adjacent pair of T-tubules is a sarcomere of which there are 75-100 in each myocyte. Along the T-tubules (and to a lesse degree the cell surface) lie dyadic junctions, the functional units of cardiac excitation-contraction coupling. Note that within a cardiac myocyte, these dyads are arranged in a 3-dimensional lattice throughout the cell (see Brette

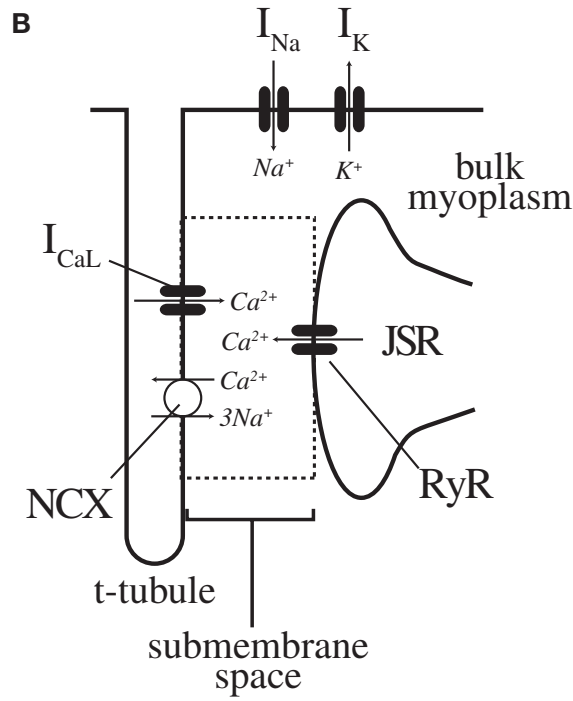

and Orchard, 2003) for more detail). (B) Each dyadic junction itself consists of the close apposition of a junctional branch of the SR with the sarcolemma, and contains the L-type $\mathrm{Ca}^{2+}$ channels and RyRs (in the sarcolemma and SR, respectively) necessary for $\mathrm{CICR}$. A single myocyte contains on the order of $10^{4}$ of these dyads arranged in a regular array, and the global $\mathrm{Ca}^{2+}$ transient is the summation of several thousand individual release events $\left(\mathrm{Ca}^{2+}\right.$-sparks) occurring at these sites. For a more complete description of specific ionic currents, see Shiferaw and Karma (2006), from which this figure was adapted.
CICR has been shown to occur at discrete subcellular sites within cardiac myocytes at which there is close apposition of the sarcolemmal membrane and a terminal cistern of the SR (“junctional SR" (JSR)), separated by a small ( $\sim 12 \mathrm{~nm}$ wide) submembrane space (Cheng and Lederer, 2008). An individual cardiac myocyte contains on the order of $10^{4}$ of these so-called "dyads" (alternatively, "dyadic junctions," or "couplons") arranged in a regular lattice (Figure 3; Brette and Orchard, 2003). These dyadic junctions are now understood to be the functional units of cardiac excitation-contraction coupling, with each containing approximately 10-25 L-type $\mathrm{Ca}^{2+}$ channels and 100 RyRs in the sarcolemmal and SR membrane, respectively (Bers, 2002; Keurs and Boyden, 2007).

During a normal $\mathrm{Ca}^{2+}$ transient, small $\mathrm{Ca}^{2+}$ releases (" $\mathrm{Ca}^{2+}$ sparks") occur independently at several thousand dyadic junctions, spatially and temporally synchronized by the AP such that the global $\mathrm{Ca}^{2+}$ transient appears uniform throughout the cell (Bers, 2002). Graded release occurs by statistical recruitment of these independent (all-or-none) release events, with larger $\mathrm{I}_{\mathrm{CaL}}$ leading to the recruitment of more dyadic junctions and thereby a larger global $\mathrm{Ca}^{2+}$ transient (Stern et al., 1999; Greenstein and Winslow, 2002). This spatial distribution of $\mathrm{Ca}^{2+}$ release is manifest in several subcellular phenomena including $\mathrm{Ca}^{2+}$-waves and subcellular alternans (described below), and illustrates the importance of subcellular $\mathrm{Ca}^{2+}$-dynamics in myocyte physiology (Díaz et al., 2002; Kockskämper and Blatter, 2002; Blatter, 2003; Xie and Weiss, 2009; Bayer et al., 2010).

Termination of contraction is accomplished by transport of $\mathrm{Ca}^{2+}$ out of the cytosol, primarily through SR reuptake (via
SR $\mathrm{Ca}^{2+}$ ATPase (SERCA) pumps) and extrusion through the sarcolemmal $\mathrm{Na}^{+} / \mathrm{Ca}^{2+}$ exchanger (NCX). The $3 \mathrm{Na}^{+}: 1 \mathrm{Ca}^{2+}$ stoichiometry of the NCX makes this exchange electrogenic, and the depolarizing current resulting from $\mathrm{Ca}^{2+}$ extrusion plays an important role in maintaining the late plateau phase of the AP (Katz, 2005).

In addition to the NCX, the $\mathrm{Ca}^{2+}$ transient influences AP morphology through several other $\mathrm{Ca}^{2+}$-sensitive membrane currents, including the L-type $\mathrm{Ca}^{2+}$ channel (Salama, 2006; Bers, 2008; Orchard et al., 2009). The rise in free $\mathrm{Ca}^{2+}$ concentration during the $\mathrm{Ca}^{2+}$ transient increases the rate of inactivation of L-type $\mathrm{Ca}^{2+}$ channels (" $\mathrm{Ca}^{2+}$-induced inactivation") through a calmodulin dependent process (Peterson et al., 1999; Mahajan et al., 2008), thereby promoting repolarization of the membrane. The balance of these depolarizing and hyperpolarizing effects of the $\mathrm{Ca}^{2+}$ transient has important consequences for myocyte dynamics, as described below.

\section{TISSUE-LEVEL ALTERNANS}

Optical mapping techniques using membrane voltage sensitive dyes have shown that TWA seen on the ECG is a manifestation of an underlying alternation in consecutive APDs of cardiac myocytes in large regions of myocardium (Pastore et al., 1999). Using $\mathrm{Ca}^{2+}$-sensitive dyes, this APD-alternans is seen to be accompanied by concurrent alternations in the amplitude of intracellular $\mathrm{Ca}^{2+}$ transients (Pruvot et al., 2004; Diego et al., 2008). The relationship between APD-alternans and $\mathrm{Ca}^{2+}$ transient alternans in tissue have been studied by experimental and model-based approaches (Narayan et al., 2008; Bayer et al., 2010). Tissue-level 


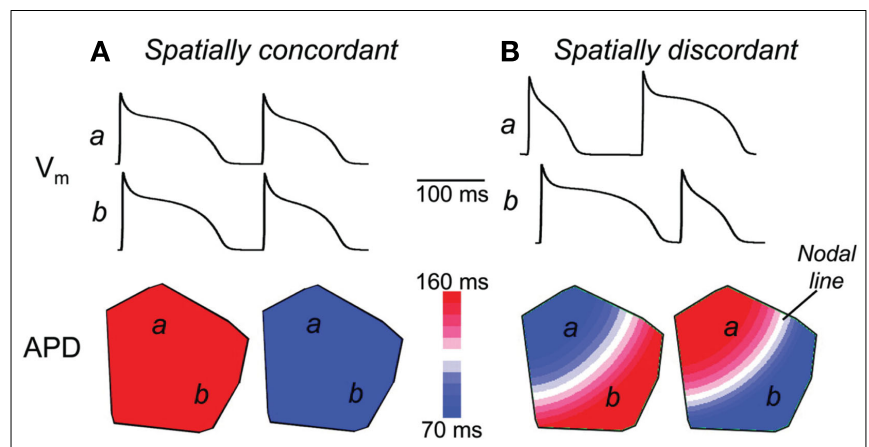

FIGURE 4 | Spatially concordant and discordant alternans in simulated cardiac tissue. Shown are the results of rapidly pacing a 2-dimensional homogeneous sheet of simulated cardiac tissue (from the top left corner), including the spatial distribution of action potential durations (bottom) and the action potentials occurring at two sites in the tissue (top traces). (A) During pacing at a cycle length of $220 \mathrm{~ms}$, spatially concordant alternans is seen, in which the APD of all myocytes alternate in-phase. (B) Pacing at a cycle length of $180 \mathrm{~ms}$, however, induces spatially discordant alternans, in which the action potentials of adjacent regions of tissue alternate out-of-phase. This is seen in the top traces, where the action potentials of site $a$ alternate short-long at the same time as those of site $b$ alternate long-short. As seen in the bottom panel, this spatially discordant alternans causes a large gradient in APD across the tissue, with large regions of tissue with counter-phase APD-alternans, separated by a "nodal line" where alternans is not seen (and where the APD gradient is steepest). Adapted from Weiss et al. (2006).

alternans normally arises as spatially concordant alternations in the APDs (and $\mathrm{Ca}^{2+}$ transients) of myocytes in large regions of tissue (Figure 4A). Although this "spatially concordant alternans" (SCA) itself is not believed to be a pro-arrhythmic state, it is usually requisite for progression to so-called "spatially discordant alternans" (SDA), which has been mechanistically linked to conduction block and the initiation of reentrant arrhythmias (Wilson and Rosenbaum, 2007).

SDA normally arises at faster pacing cycle lengths than SCA, when the alternations in APD (and $\mathrm{Ca}^{2+}$ transients) switch phase in a subset of myocytes, leading to out-of-phase alternations in adjacent regions of tissue (Figure 4B). Although the APD gradient seen in SDA was initially attributed to preexisting spatial heterogeneity in the expression of ion channels important for repolarization (Pastore et al., 1999), several mechanisms have since been proposed in which SDA can arise in homogeneous tissue (Watanabe et al., 2001).

Experimental and theoretical studies have shown that ratedependent transition from SCA to SDA can occur by a purely dynamical phenomenon, dependent on only the interaction of conduction velocity and action potential duration restitution (Watanabe et al., 2001; Sato et al., 2007; Diego et al., 2008). Specifically, during APD-alternans conduction velocity restitution (described above) leads to an alternation in the propagation speed of waves of excitation (i.e., fast-slow-fast). Given sufficiently sized tissue, the resulting alternation in arrival times (and thereby in the local diastolic interval) of these depolarizing stimuli at more distant sites can cause alternations in the APD (due to APD restitution, as above) that are out-of-phase with those more proximal. See Watanabe et al. (2001) and Echebarria and Karma (2007)

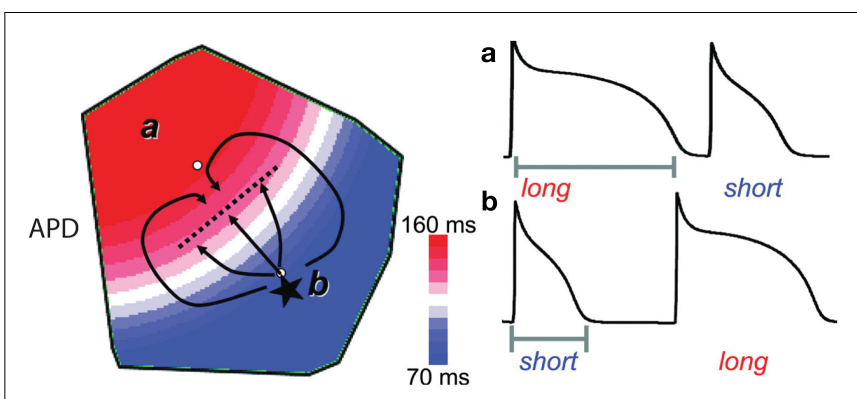

FIGURE 5 | Spatially discordant alternans predisposes premature excitations to induce conduction block and reentry. One mechanism by which SDA predisposes otherwise benign premature beats to conduction block and reentry is diagrammed. An ectopic beat (asterisk) initiated during SDA in the region with a short APD encounters more refractory tissue as it propagates toward the region with long APD. Given a sufficiently steep gradient of refractoriness, conduction block can occur (dashed line).

Meanwhile, this beat can successfully propagate laterally, allowing time for recovery of the long APD region and subsequent reentry. Adapted from Weiss et al. (2006).

for a qualitative and quantitative description, respectively, of this phenomenon. Notably, SDA can also be induced if a propagated ectopic stimulus initiated distant from the pacing site causes a sufficient gradient in the subsequent diastolic interval (Watanabe et al., 2001).

SDA is putatively linked to the initiation of reentry by the formation of steep gradients of refractoriness across the myocardium. Such steep gradients of refractoriness have been shown computationally and experimentally to precipitate unidirectional conduction block and functional reentry, even in homogeneous tissue (as diagrammed in Figure 5; Chinushi et al., 1998; Pastore et al., 1999; Qu et al., 2000; Fox et al., 2002b). Notably, the dynamic transition to SDA described above has been shown to arise more readily in structurally heterogenous tissue, potentially contributing to the predisposition to reentrant tachyarrhythmias in humans with structural heart disease (Krogh-Madsen and Christini, 2007).

\section{CELLULAR ALTERNANS}

TWA on the ECG is understood to be a manifestation of underlying APD-alternans in individual myocytes, but the mechanism by which this cellular alternans arises remains unclear. As in tissuelevel alternans, studies in enzymatically isolated cardiac myocytes have shown rapid pacing (faster than a critical threshold) to induce alternations in the APD and the $\mathrm{Ca}^{2+}$ transient amplitude (as in Figures 2B and 6A), with altered susceptibility in myocytes from the diseased heart (Chudin et al., 1999; Willms et al., 1999).

Determining the mechanism of cellular alternans is complicated by the multiple possible sources of instability. Theoretical and experimental work has identified mechanisms by which APD-alternans and $\mathrm{Ca}^{2+}$-alternans (beat-to-beat alternations in the peak $\mathrm{Ca}^{2+}$ transient magnitude) can result independently from one another, due only to instability in sarcolemmal ion channel and intracellular $\mathrm{Ca}^{2+}$-cycling dynamics, respectively. As described below, in each case the mechanism is thought to be a manifestation of a so-called "period-doubling bifurcation," a phenomenon of non-linear dynamical systems in which a periodic 


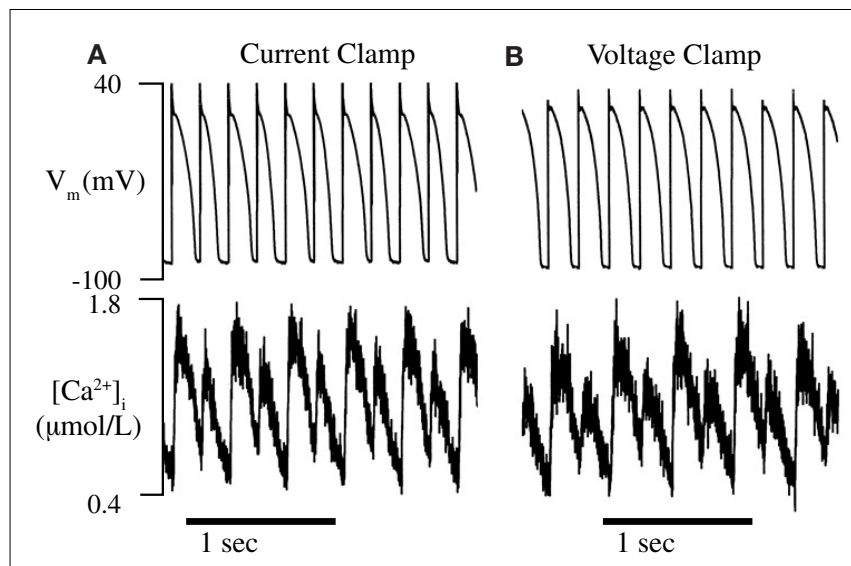

FIGURE 6 | Alternans can be caused by intrinsic $\mathrm{Ca}^{2+}$-cycling dynamics alone. The intracellular $\mathrm{Ca}^{2+}$ transients of paced (A) and AP clamped (B) isolated rabbit ventricular myocytes are observed using a fluorescent $\mathrm{Ca}^{2+}$-sensitive dye (fura-2). (A) As expected, the APDs and $\mathrm{Ca}^{2+}$ transients of paced myocytes are seen to alternate from beat-to-beat when the cycle length is reduced to below a critical threshold $(180 \mathrm{~ms})$. (B) The $\mathrm{Ca}^{2+}$ transients of AP clamped myocytes were still seen to alternate below approximately the same cycle length threshold as paced myocytes, in spite of fixed membrane voltage. This indicates that $\mathrm{Ca}^{2+}$-cycling dynamics can alternate due to their own, intrinsic instability and has led many to conclude that $\mathrm{Ca}^{2+}$-dynamics are solely responsible for cellular alternans. Adapted from Chudin et al. (1999).

rhythm is replaced by another with twice the period. In this case, a stable "period-1" rhythm, in which each beat's APD and $\mathrm{Ca}^{2+}$ transient are identical, are replaced by a new "period-2" (alternans) rhythm, in which these values alternate from beat-to-beat.

The APD and $\mathrm{Ca}^{2+}$ transient are bidirectionally coupled, however, and alternations in either one is predicted to cause secondary alternans in the other, making determination of the primary source of instability a difficult experimental challenge (Qu and Weiss, 2007). This coupling naturally leads to two hypotheses: (1) instability in membrane voltage dynamics causes APD-alternans, producing secondary alternations in the intracellular $\mathrm{Ca}^{2+}$ transient (Guevara et al., 1984; Koller et al., 1998; Riccio et al., 1999; Watanabe et al., 2001; Fox et al., 2002b) and (2) instability in $\mathrm{Ca}^{2+}$-cycling dynamics causes alternans in the intracellular $\mathrm{Ca}^{2+}$ transient, producing secondary APD-alternans (Chudin et al., 1999; Hüser et al., 2000; Díaz et al., 2002, 2004; Pruvot and Rosenbaum, 2003; Goldhaber et al., 2005; Wan et al., 2005). Although mechanism (1) was favored for many years, recent experimental evidence has shifted the majority of focus to mechanism (2), with many in the field treating alternans as resulting from $\mathrm{Ca}^{2+}$-cycling dynamics alone. As described below, however, such a dichotomy is unlikely to exist in real cells.

\subsection{VOLTAGE (RESTITUTION) DRIVEN ALTERNANS}

The first widely accepted theory of cellular alternans considered only the time-dependent recovery of sarcolemmal ion channels. This " $\mathrm{V}_{\mathrm{m}}$-driven alternans" theory centers on the APD restitution relationship, employing a simple model of myocyte dynamics in which the APD is a function solely of the preceding DI.

The role of APD restitution in alternans is diagrammed in Figure 7. During constant cycle length ("static") pacing, a

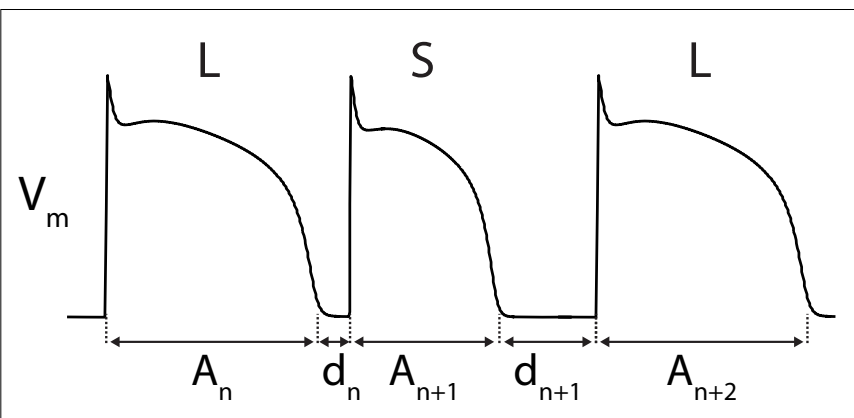

FIGURE 7 | Diagram of APD-alternans. APD-alternans can theoretically occur due to APD restitution alone $\left(\mathrm{V}_{\mathrm{m}}\right.$-driven alternans). See text for description.

prolonged APD $\left(A_{n}\right)$ shortens the subsequent DI $\left(d_{n}\right)$. APD restitution dictates that this short DI will lead to a shortened subsequent $\mathrm{AP}\left(A_{n+1}\right)$, which will be followed by a long subsequent DI $\left(d_{n+1}\right)$. This long DI will lead to another long APD $\left(A_{n+2}\right)$, and the pattern is thus repeated (Shiferaw et al., 2006). The alternating DIs during this rhythm will also cause a secondary $\mathrm{Ca}^{2+}$-alternans, due to alternating time for recovery of $\mathrm{I}_{\mathrm{CaL}}$ (and graded release of $\left.\mathrm{SR} \mathrm{Ca}^{2+}\right)$.

This mechanism was first proposed in a seminal 1968 article by Nolasco and Dahlen (1968), in which an analogy to a simple electronic feedback circuit (in which the APD feeds back on itself through changes in the DI) was drawn and the principles of electrical engineering were used to account for the occurrence of alternans. Their model is equivalent to the iterated map

$A_{n+1}=f\left(d_{n}\right)$,

where $A_{n}$ and $d_{n}$ are the APD and diastolic interval, respectively, of beat $n$ and $A_{n}+d_{n}$ is a constant (the cycle length). Here, $f$ is the restitution function describing the dependence of APD on the preceding diastolic interval (Karma and Gilmour, 2007). In this map, alternans occurs when its period-1 fixed point (where APD and DI are constant) loses stability and is replaced by a period2 rhythm (alternating APDs). This period-doubling bifurcation occurs when

$f^{\prime}=\left.\frac{d f}{d d_{n}}\right|_{d_{n}=d^{*}}>1$,

where $f^{\prime}$ represents the slope of the restitution curve, evaluated at the steady-state DI ( $d^{*}$; Guevara et al., 1984). Assuming a monotonic restitution curve, this condition predicts that given sufficiently steep APD restitution $\left(f^{\prime}>1\right)$, small changes in DI will be amplified into stable alternations of APD (alternans; Nolasco and Dahlen, 1968; Guevara et al., 1984; Karma and Gilmour, 2007).

This hypothesis has been supported by theoretical and experimental studies showing the occurrence of arrhythmia to correlate with the slope of the APD restitution curve, including several experimental studies in which existing arrhythmias are abolished using (clinically impractical) drugs that flatten restitution (Riccio et al., 1999; Garfinkel et al., 2000; Wu et al., 2002). This model fails, however, to explain many other experimental findings (Franz, 
2003). For example, alternans is often seen at pacing rates where the slope of the experimentally determined restitution curve is significantly less than 1 (as in Figure 2), and is often absent where the slope is greater than 1 (Gilmour et al., 1997; Otani and Gilmour, 1997; Hall et al., 1999; Banville and Gray, 2002; Banville et al., 2004; Pruvot et al., 2004; Wu and Patwardhan, 2004, 2006). Moreover, the restitution slope measured experimentally varies depending on the pacing history of the cell (so-called "cardiac memory"), which would not be the case if the APD is truly dependent only on the previous DI (Tolkacheva et al., 2004, 2006). Alternans must result from more than this simple relationship, and mounting experimental evidence is implicating intracellular $\mathrm{Ca}^{2+}$-cycling dynamics as a major overlooked component in this scheme.

\subsection{CALCIUM-DRIVEN ALTERNANS}

As with the APD, beat-to-beat alternations in the magnitude of intracellular $\mathrm{Ca}^{2+}$ transients can occur due to intrinsic $\mathrm{Ca}^{2+}$ cycling dynamics alone. This " $\mathrm{Ca}^{2+}$-driven alternans" will lead to secondary APD-alternans due to $\mathrm{Ca}^{2+}$-sensitive membrane components (e.g., L-type $\mathrm{Ca}^{2+}$ channels and the NCX). This hypothesis has received the majority of recent focus, due in large part to two in vitro studies that showed $\mathrm{Ca}^{2+}$-alternans to occur even while the membrane voltage was clamped to follow a repeating (nonalternating) AP waveform (Figure 6; Chudin et al., 1999; Wan et al., 2005). During such "AP Clamp" experiments, the clamped period-1 AP cannot produce secondary alternations in $\mathrm{Ca}^{2+}$ transients, making any $\mathrm{Ca}^{2+}$-alternans seen in that context the result of $\mathrm{Ca}^{2+}$-cycling dynamics alone.

There are several proposed mechanisms by which intrinsic $\mathrm{Ca}^{2+}$-cycling dynamics can lead to rate-dependent alternans, but once again no one mechanism is likely to be the source of the instability seen. For stable control of SR $\mathrm{Ca}^{2+}$ content (and therefore $\mathrm{Ca}^{2+}$ transient amplitude), the amount of $\mathrm{Ca}^{2+}$ released from the SR during each beat must equal the amount reclaimed. $\mathrm{Ca}^{2+}$-alternans will occur as a result of intrinsic $\mathrm{Ca}^{2+}$-cycling dynamics whenever this capability of the myocyte to cycle $\mathrm{Ca}^{2+}$ is overwhelmed (Cutler and Rosenbaum, 2009). The most studied mechanism by which this can occur is by a steep load dependence of $\mathrm{SR} \mathrm{Ca}^{2+}$ release, as follows.

The amount of $\mathrm{Ca}^{2+}$ released from the SR is known to be dependent on the load of $\mathrm{Ca}^{2+}$ it contains, with increased SR $\mathrm{Ca}^{2+}$-content resulting in a larger $\mathrm{Ca}^{2+}$ release and vice versa (Bassani et al., 1995; Díaz et al., 2004). Likewise, the amount of $\mathrm{Ca}^{2+}$ reclaimed into the SR is dependent on the amount of $\mathrm{Ca}^{2+}$ available in the cytosol. Alternations in SR $\mathrm{Ca}^{2+}$-content (and release) will result given either a steep load dependence of $\mathrm{SR} \mathrm{Ca}^{2+}$ release or inefficient $\mathrm{Ca}^{2+}$-sequestration into the SR (Shiferaw et al., 2006).

As an example, consider the effect on $\mathrm{Ca}^{2+}$-cycling of an increase in SR $\mathrm{Ca}^{2+}$ content above its baseline. Due to the load dependence of SR $\mathrm{Ca}^{2+}$ release, this will increase the amount of $\mathrm{Ca}^{2+}$ released from the SR with the next stimulus. If this release depresses SR $\mathrm{Ca}^{2+}$ content to the extent that reuptake is unable to return it to its baseline level before the next stimulus, a smaller subsequent $\mathrm{Ca}^{2+}$ release will result (due to the decreased SR load). This smaller release will cause less depletion of SR $\mathrm{Ca}^{2+}$. If this depletion is sufficiently small, reuptake will refill the SR to above its baseline $\mathrm{Ca}^{2+}$ content once again before the next stimulus. Whether these alternations in SR $\mathrm{Ca}^{2+}$ content (and release) shrink toward a stable rhythm (at the baseline SR Ca ${ }^{2+}$ content) or grow into a marked $\mathrm{Ca}^{2+}$-alternans depends on both the steepness of the load dependence of SR $\mathrm{Ca}^{2+}$ release and the efficiency of $\mathrm{Ca}^{2+}$-reuptake (Weiss et al., 2006; Xie et al., 2008). Although $\mathrm{Ca}^{2+}$-alternans will theoretically result given either a steep load dependence or inefficient reuptake, the latter has yet to be explored in detail.

Figure 8 shows the relationship between $\mathrm{SR} \mathrm{Ca}^{2+}$ content and release, determined experimentally in rat ventricular myocytes (Díaz et al., 2004). The load dependence of SR $\mathrm{Ca}^{2+}$ release is quantified as the slope of this curve. These results (as well as those of other studies; Bassani et al., 1995) show the dependence to be highly non-linear, with a steep slope at those SR $\mathrm{Ca}^{2+}$ contents at which alternans is seen (filled circles). Rate-dependent, $\mathrm{Ca}^{2+}$ driven alternans can occur by this mechanism due to increasing SR $\mathrm{Ca}^{2+}$-content with faster pacing (Shiferaw et al., 2003; Díaz et al., 2004). This non-linearity at high SR $\mathrm{Ca}^{2+}$ loads is primarily attributed to the triggering of propagating waves of $\mathrm{Ca}^{2+}$ release when SR release is sufficiently large to recruit neighboring dyadic junctions (discussed below; Shiferaw et al., 2003). This steep non-linearity in load dependence has been incorporated in a computational model of a cardiac myocyte and shown to cause to $\mathrm{Ca}^{2+}$-driven alternans (Shiferaw et al., 2003).

A less studied, alternative mechanism (among several) predicts that $\mathrm{Ca}^{2+}$-alternans can be induced without alternations in the SR $\mathrm{Ca}^{2+}$ concentration (the existence of which is contentious), due to slow recovery from inactivation of Ryanodine receptors. Similar to the dynamics of sarcolemmal ion channels during rapid pacing, if recovery from inactivation is sufficiently slow as to only allow full recovery after every other release, alternations in the $\mathrm{Ca}^{2+}$ transient magnitude $\left(\mathrm{Ca}^{2+}\right.$-alternans) will result (Picht et al., 2006; Restrepo et al., 2008).

\subsection{BIDIRECTIONAL COUPLING OF VOLTAGE AND CALCIUM}

As described above, the APD and the intracellular $\mathrm{Ca}^{2+}$ transient are coupled to one another through mutual effects on intracellular $\mathrm{Ca}^{2+}$ concentration, leading APD-alternans to generate

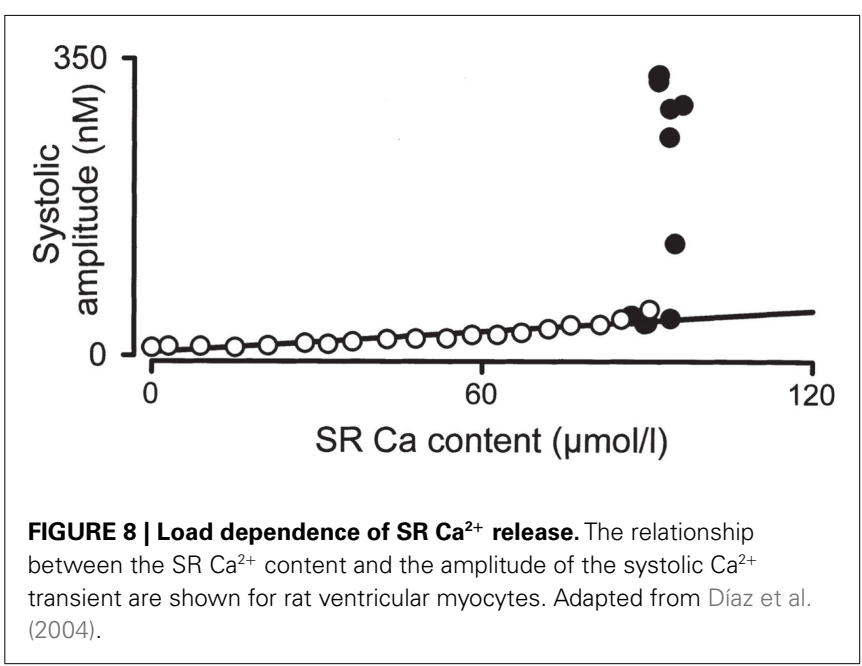


secondary $\mathrm{Ca}^{2+}$-alternans and vice versa. Several modes of coupling are possible, however, and the specific type present has recently been shown to dictate important characteristics of the resulting alternans.

The duration of each AP influences the intracellular $\mathrm{Ca}^{2+}$ transient through the phenomenon of graded release, in which the magnitude of the SR calcium release of each beat is proportional to the size of its triggering L-type calcium channel current ("graded release"). Because $\mathrm{I}_{\mathrm{CaL}}$ is itself very dependent on the length of the preceding diastolic interval (due to slow recovery from inactivation), a shortened diastolic interval leads to a smaller subsequent $\mathrm{Ca}^{2+}$ release and vice versa (Figure 9A). As such, during static pacing (when APD + DI is constant), prolongation of the APD causes a shortening of the subsequent diastolic interval and a smaller $\mathrm{Ca}^{2+}$ release on the following beat. This is defined as "positive $\mathrm{V}_{\mathrm{m}} \rightarrow \mathrm{Ca}^{2+}$ coupling." Note that although this effect is, directly, a manifestation of $\mathrm{V}_{\mathrm{m}}$ (specifically the $\mathrm{I}_{\mathrm{CaL}}$-mediated plateau) on the $\mathrm{Ca}^{2+}$ transient of the same beat (through CICR), the strong dependence of $\mathrm{I}_{\mathrm{CaL}}$ itself on the preceding DI allows $\mathrm{V}_{\mathrm{m}} \rightarrow \mathrm{Ca}^{2+}$ coupling to be modeled as an effect of APD on the amplitude of the subsequent $\mathrm{Ca}^{2+}$ transient (Figure 9A, red arrow).

Due to positive $\mathrm{V}_{\mathrm{m}} \rightarrow \mathrm{Ca}^{2+}$ coupling, the DI alternations seen during $\mathrm{V}_{\mathrm{m}}$-driven alternans will produce secondary $\mathrm{Ca}^{2+}$ alternans that are in-phase with the primary APD-alternans (Shiferaw et al., 2006). This is called electromechanically (EM) concordant alternans, and is a common experimental observation. Although negative $\mathrm{V}_{\mathrm{m}} \rightarrow \mathrm{Ca}^{2+}$ coupling (and resulting EM discordant alternans) is theoretically possible at slower pacing rates, it has not been reported experimentally and positive $\mathrm{V}_{\mathrm{m}} \rightarrow \mathrm{Ca}^{2+}$ coupling is normally assumed (Shiferaw et al., 2005; Weiss et al., 2006).

Similarly, changes in intracellular $\mathrm{Ca}^{2+}$ concentration can be positively or negatively coupled to the APD through the opposing effects of the sodium-calcium exchanger and $\mathrm{Ca}^{2+}$-induced inactivation of L-type $\mathrm{Ca}^{2+}$ channels. So-called "positive $\mathrm{Ca}^{2+} \rightarrow \mathrm{V}_{\mathrm{m}}$

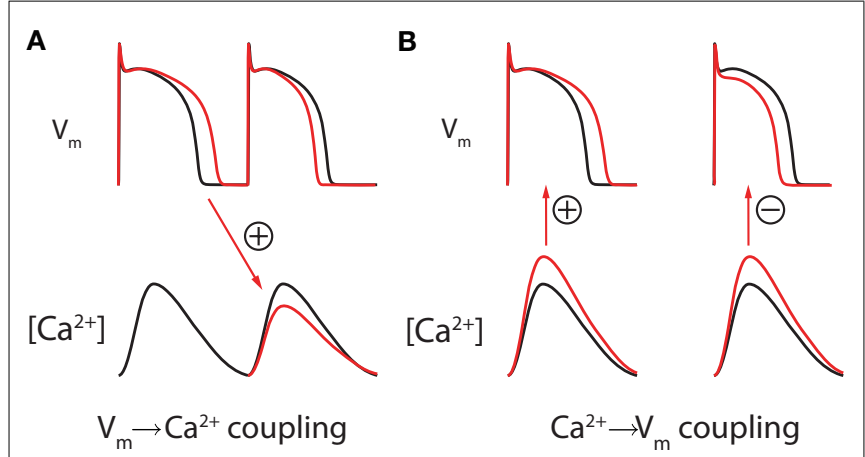

FIGURE 9 | Bidirectional coupling of $\mathbf{V}_{m}$ and $\mathbf{C a}^{2+}$. (A) During static pacing, $V_{m} \rightarrow \mathrm{Ca}^{2+}$ coupling is assumed to be positive due to graded release (as shown). An increase in the preceding APD leads to a decrease in the subsequent $\mathrm{Ca}^{2+}$ transient (due to a shortening of the diastolic interval), and vice versa. Note that this change in DI will also have an APD restitution mediated effect on the subsequent APD (in this case, shortening it). (B) $\mathrm{Ca}^{2+} \rightarrow \mathrm{V}_{\mathrm{m}}$ coupling can be either positive (left) or (right), dependent on species, cell type, and temperature. Adapted from Gaeta et al. (2010). coupling" occurs when the depolarizing effect of NCX calcium extrusion is stronger than the hyperpolarizing effect of $\mathrm{Ca}^{2+}$. induced inactivation of L-type $\mathrm{Ca}^{2+}$ channels. In this case, an increase in the amplitude of the $\mathrm{Ca}^{2+}$ transient will prolong the concurrent AP. Alternatively, if the effect of $\mathrm{Ca}^{2+}$-induced inactivation of L-type $\mathrm{Ca}^{2+}$ channels outweighs that of the NCX, changes in intracellular $\mathrm{Ca}^{2+}$ concentration will be negatively coupled to $\mathrm{V}_{\mathrm{m}}$ and larger $\mathrm{Ca}^{2+}$ transients will shorten the AP (Figure 9B; Shiferaw et al., 2005).

During $\mathrm{Ca}^{2+}$-driven alternans, the sign of $\mathrm{Ca}^{2+} \rightarrow \mathrm{V}_{\mathrm{m}}$ coupling dictates whether the secondary APD-alternans produced will be in-phase or out-of-phase with the primary $\mathrm{Ca}^{2+}$-alternans. Given positive $\mathrm{Ca}^{2+} \rightarrow \mathrm{V}_{\mathrm{m}}$ coupling, large $\mathrm{Ca}^{2+}$ transients will prolong the APD, thereby predicting EM concordant alternans. If, however, $\mathrm{Ca}^{2+} \rightarrow \mathrm{V}_{\mathrm{m}}$ coupling is negative, large $\mathrm{Ca}^{2+}$ transients will shorten concurrent APs and EM discordant alternans (in which $\mathrm{APD}$-alternans and $\mathrm{Ca}^{2+}$-alternans occur out-of-phase) will result (Shiferaw et al., 2006).

Although this property remains poorly characterized, the relative phase of APD and $\mathrm{Ca}^{2+}$-alternans appears to be a species and/or temperature-specific property of myocytes. Both EM concordant and EM discordant alternans have been reported in the literature (Rubenstein and Lipsius, 1995; Euler, 1999).

\subsection{ALTERNANS IS THE RESULT OF TOTAL CELLULAR INSTABILITY}

The dichotomy between membrane voltage and $\mathrm{Ca}^{2+}$-cycling dynamics as the cause of alternans ignores the interplay between these two systems in a normal myocyte. In an unclamped cell, neither of these two mechanisms is likely to be the sole cause of alternans. $\mathrm{Ca}^{2+}$-cycling dynamics are always directly modulated by the dynamics of membrane voltage, and thus both likely contribute to the onset of alternans (Jordan and Christini, 2007; Qu and Weiss, 2007). Just as alternans is seen at cycle lengths with restitution slope $<1$ (indicative of a non- $\mathrm{V}_{\mathrm{m}}$ mediated contribution), alternating $\mathrm{Ca}^{2+}$ transients often stabilize in the presence of an AP clamp (indicative of non- $\mathrm{Ca}^{2+}$ mediated influence; personal observation of experimental results). This was supported by a recent computational modeling study, in which a cycle length and cell type dependent contribution of both $\mathrm{V}_{\mathrm{m}}$ and $\mathrm{Ca}^{2+}$-cycling instability to cellular alternans was found in mathematical models (Jordan and Christini, 2007).

\section{SUBCELLULAR ALTERNANS}

Recently, so-called "subcellular alternans" (also known as "subcellular spatially discordant alternans") has been observed, in which the $\mathrm{Ca}^{2+}$-alternans in adjacent subcellular regions within an individual myocyte alternate out-of-phase (as in Figures 10 and 11). This striking phenomenon has been frequently (though often anecdotally) reported in isolated myocytes (Díaz et al., 2002, 2004; Kockskämper and Blatter, 2002; Cordeiro et al., 2007; Karma and Gilmour, 2007; Gaeta et al., 2009) and within individual cells of the intact heart during rapid pacing (Aistrup et al., 2006, 2009; Kapur et al., 2009).

Subcellular alternans is known to cause intracellular $\mathrm{Ca}^{2+}$. waves, which are potentially arrhythmogenic. $\mathrm{Ca}^{2+}$-waves are self-propagating waves of $\mathrm{Ca}^{2+}$ release (and subsequent reuptake) within individual myocytes, that are most often seen when 

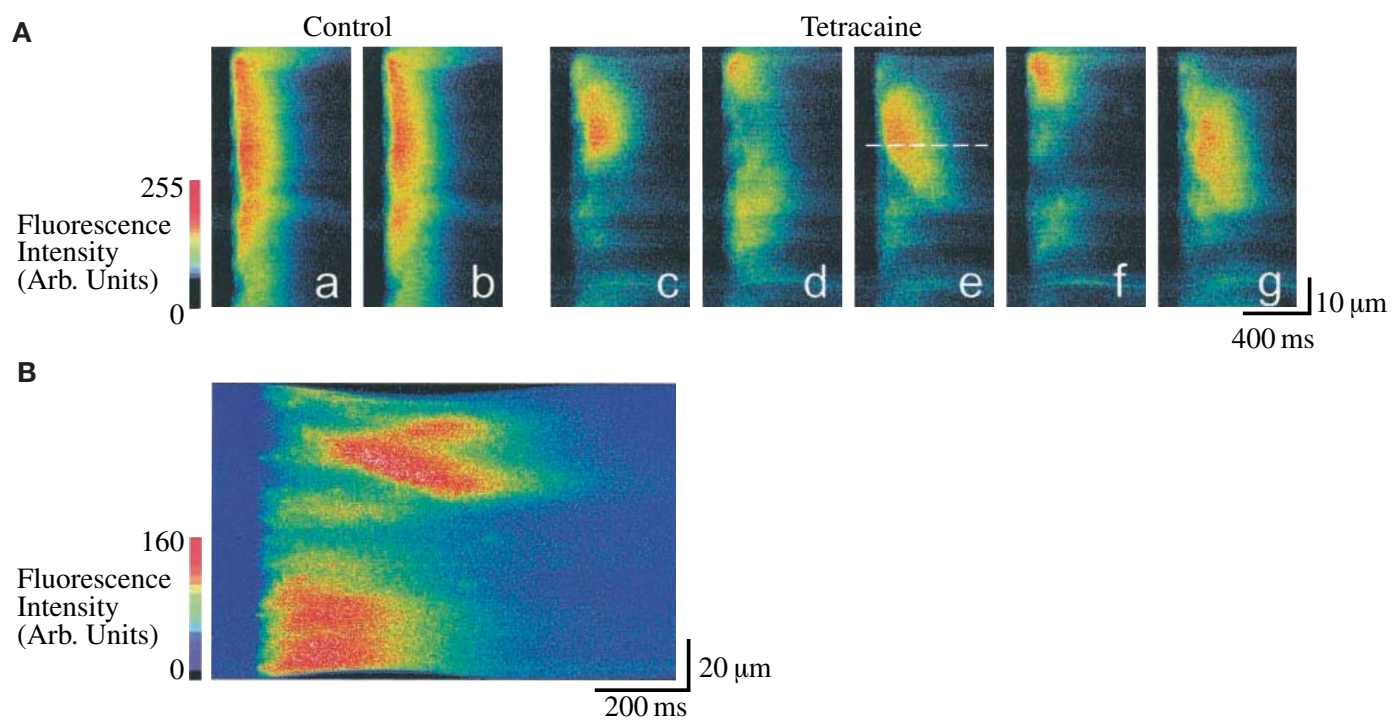

FIGURE 10 | Tetracaine induced subcellular alternans in rat ventricular myocytes. Confocal microscopy is used to study the spatial organization of the $\mathrm{Ca}^{2+}$ transient during control conditions and during treatment with Tetracaine (causing decreased RyR open probability and an increased subcellular heterogeneity in $\mathrm{Ca}^{2+}$ release). The line-scan images shown correspond to the relative $\mathrm{Ca}^{2+}$ concentrations along a single line parallel to the long axis of the cell, plotted with time on the horizontal axis and distance on the vertical axis. (A) Although during control conditions (line-scan images $\mathbf{a}-\mathbf{b}$ ) the $\mathrm{Ca}^{2+}$ transient is nearly homogeneous, application of tetracaine causes a marked subcellular alternans pattern (shown in line-scan images $\mathbf{c - g}$ ). Note the mini $\mathrm{Ca}^{2+}$-wave seen to propagate away from the dashed line in e. (B) A propagating $\mathrm{Ca}^{2+}$-wave is seen to initiate from an area of steep gradient in $\mathrm{Ca}^{2+}$ concentration (obtained in tetracaine). Adapted from Díaz et al. (2002).

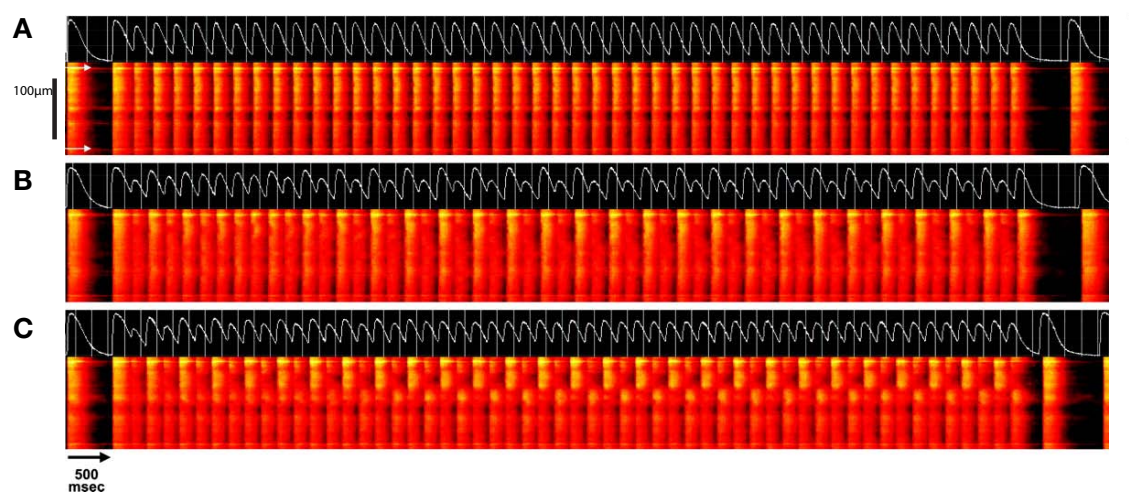

FIGURE 11 | Pacing-induced subcellular alternans in intact rat heart. The intracellular $\mathrm{Ca}^{2+}$ concentration of individual myocytes were recorded in situ within an intact rat heart using confocal line-scan imaging. a transients recorded along the long axis of a single myocyte (with cell boundaries indicated by white arrows in $(\mathbf{A})$ ), are shown. Following a train of stimuli at a cycle length of $500 \mathrm{~ms}$, the cycle length was decreased to $220 \mathrm{~ms}$ (A), $190 \mathrm{~ms}$ (B), or $180 \mathrm{~ms}$ (C) for approximately 50 stimuli, after which pacing was resumed at the original rate. In each panel, the line-scan results of the last stimulus at the basal rate, the test train at the faster cycle length, and the first beat after return to slower pacing are shown with time on the horizontal axis and position on the vertical axis. Above each of these plots is the whole-cell average $\mathrm{Ca}^{2+}$ transient of each trial (white trace). At a pacing cycle length of $220 \mathrm{~ms}$ (A), the whole-cell average calcium transient is seen to be at a period-1 rhythm and the $\mathrm{Ca}^{2+}$ transient is approximately uniform along the length of the cell. With faster pacing (B), the $\mathrm{Ca}^{2+}$ transient remains

approximately spatially uniform, but begins to alternate in amplitude from beat-to-beat (whole-cell concordant alternans). At the fastest cycle length (C), subcellular alternans develops, in which adjacent regions of the cell (the top and bottom half, roughly) alternate out-of-phase, but the whole-cell average $\mathrm{Ca}^{2+}$ transient is at a nearly period-1 rhythm. Adapted from Aistrup et al. (2006).
$\mathrm{Ca}^{2+}$ content is abnormally increased (" $\mathrm{Ca}^{2+}$-overload"; e.g., during ischemia-reperfusion and tachycardia; Sipido, 2006; Bers, 2008). These events are known to cause arrhythmogenic early and delayed afterdepolarizations through activation of $\mathrm{Ca}^{2+}$-sensitive membrane currents (especially the NCX; Minamikawa et al., 1997;
Knot et al., 2005; Keurs and Boyden, 2007; Venetucci et al., 2008; Xie and Weiss, 2009), which if sufficiently large can lead to the generation of unstimulated APs (triggered activity). As depicted in Figure 5, such ectopic, unstimulated activations are known to play a role in the initiation of reentrant arrhythmias (Miura et al., 


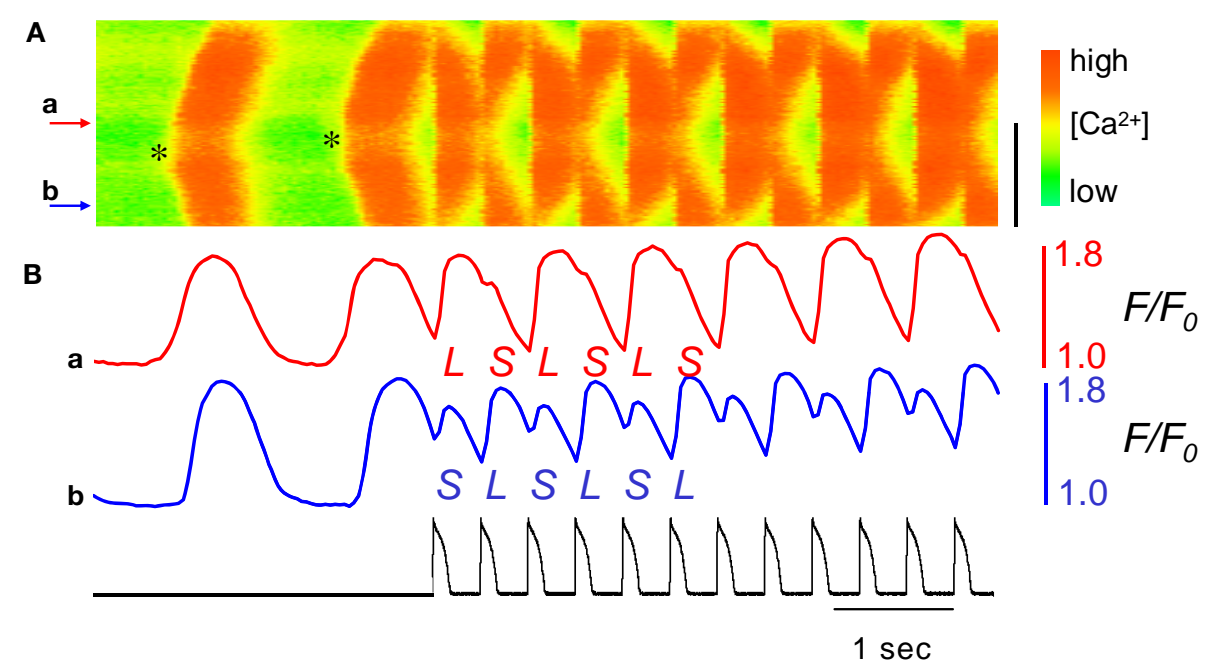

FIGURE 12 | $\mathrm{Ca}^{2+}$-waves predispose to subcellular alternans in an isolated rabbit ventricular myocyte. Line-scan data of $\mathrm{Ca}^{2+}$

fluorescence along the length of an isolated rabbit ventricular myocyte is plotted with time on the horizontal axis and distance on the vertical axis (distance scale bar is $50 \mu \mathrm{m}$ ). $\mathrm{Ca}^{2+}$-waves were induced by application of BayK8644 + Isoproterenol (thereby inducing $\mathrm{Ca}^{2+}$-overload). (A) Two spontaneous $\mathrm{Ca}^{2+}$-waves are seen to arise near the middle of the cell (near site a) and propagate outward. Beginning during the second $\mathrm{Ca}^{2+}$-wave, a repeating AP clamp was used to rapidly pace the cell (with waveform and timing as shown in (B), black trace), causing a marked subcellular alternans pattern. (B) The time series of $\mathrm{Ca}^{2+}$-fluorescence at sites $a$ and $b$ show $\mathrm{Ca}^{2+}$-alternans during the AP clamp pacing to be out-of-phase at these two points. Adapted from Xie and Weiss (2009).
1993; Ferrari et al., 1995; Fujiwara et al., 2008). Nearly every study of subcellular alternans in isolated cells, including those in which $\mathrm{Ca}^{2+}$ content was presumably normal, has shown $\mathrm{Ca}^{2+}$-waves to initiate from near the boundary between adjacent subcellular regions in which $\mathrm{Ca}^{2+}$-transients are alternating out-of-phase (where the $\left[\mathrm{Ca}^{2+}\right]_{\mathrm{i}}$ gradient is steepest; as in Figure 10B; Díaz et al., 2002, 2004; Kockskämper and Blatter, 2002; Xie and Weiss, 2009). Conversely, subcellular alternans can also be induced secondary to $\mathrm{Ca}^{2+}$-waves (described below; Xie and Weiss, 2009). A better understanding of the mechanism of subcellular alternans may help in understanding each of these phenomena and the relationship between them.

\subsection{DYNAMICAL MECHANISMS OF SUBCELLULAR ALTERNANS}

Subcellular alternans can be understood as the formation of a pattern in subcellular $\mathrm{Ca}^{2+}$ transients from an initially (approximately) spatially homogeneous state. A fundamental question when studying any such pattern formation is whether the patterns seen reflect the presence of preexisting heterogeneities of the substrate in question, dynamically induced heterogeneity, or both (Gaeta et al., 2010). Examples of each of these mechanisms has been proposed to account for pacing-induced subcellular alternans in isolated cells and intact tissue.

Although subcellular alternans has been most often reported in isolated myocytes following the application of drugs that increase subcellular heterogeneity (as in Figure 10; Díaz et al., 2002, 2004; Kockskämper and Blatter, 2002), it has also been reported in otherwise healthy cells during rapid pacing (Kockskämper and Blatter, 2002; Cordeiro et al., 2007). Whereas the former studies are likely to be most relevant to the particular disease states that they model, the latter, pacing-induced subcellular alternans represents

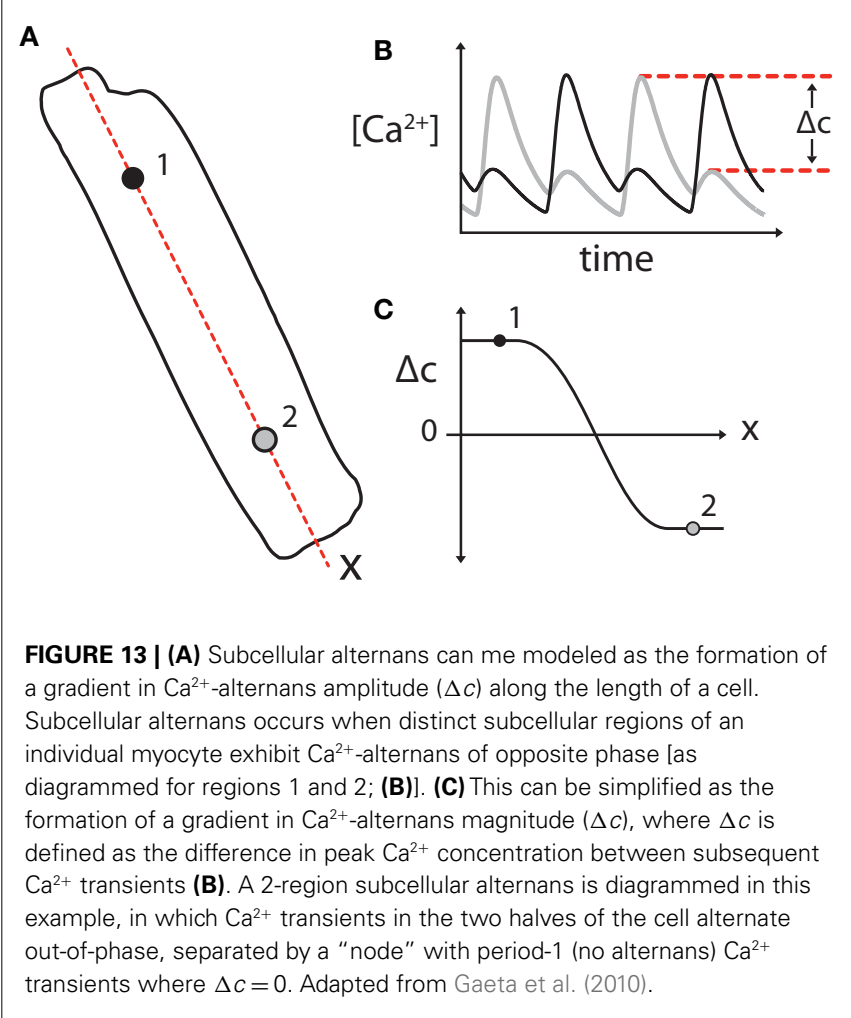

physiologic myocyte dynamics that are likely to play a role in any context. Several mechanisms have been proposed to account for the formation of subcellular alternans during rapid pacing of otherwise healthy cells, invoking either preexisting anatomical 

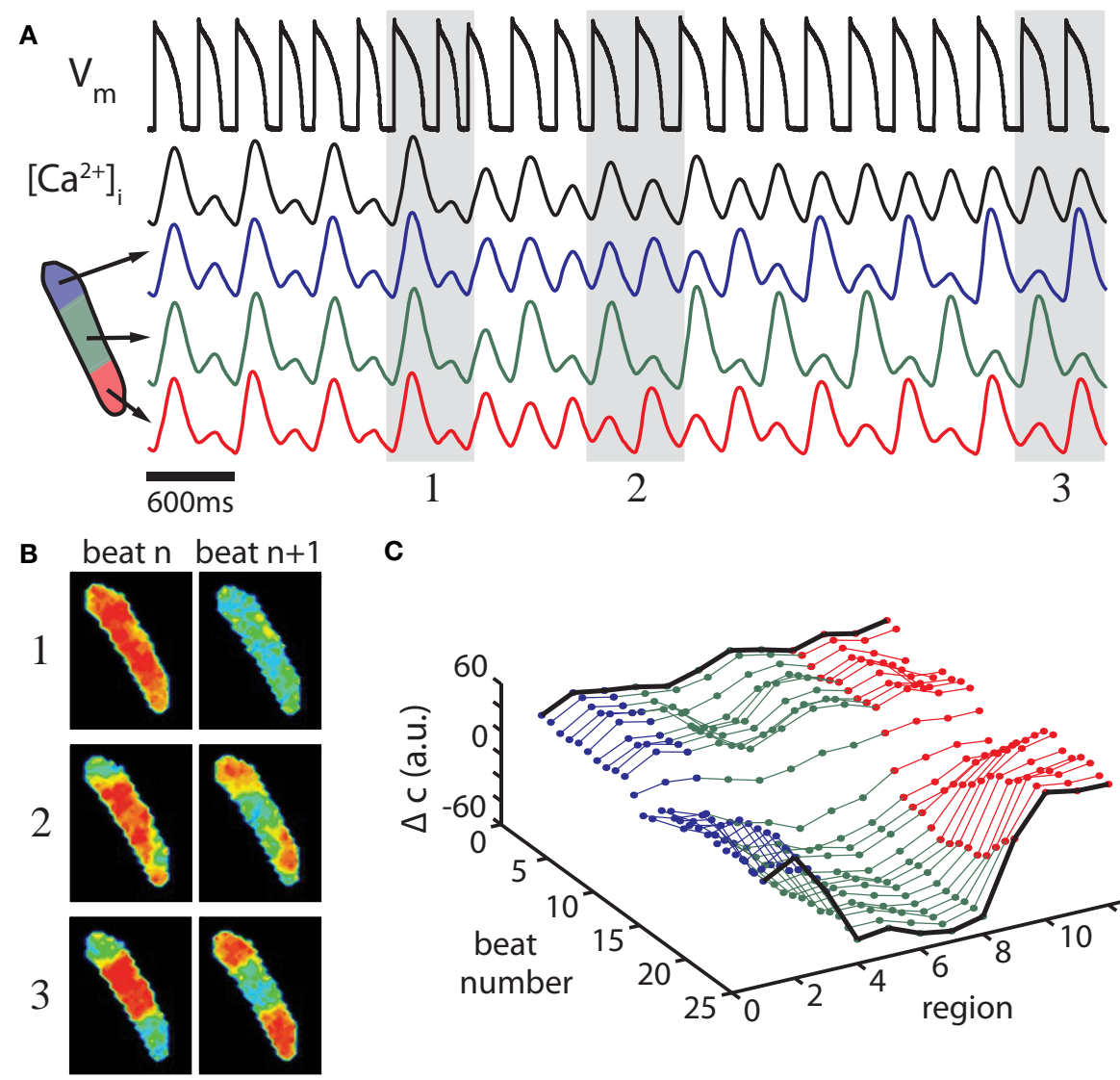

C

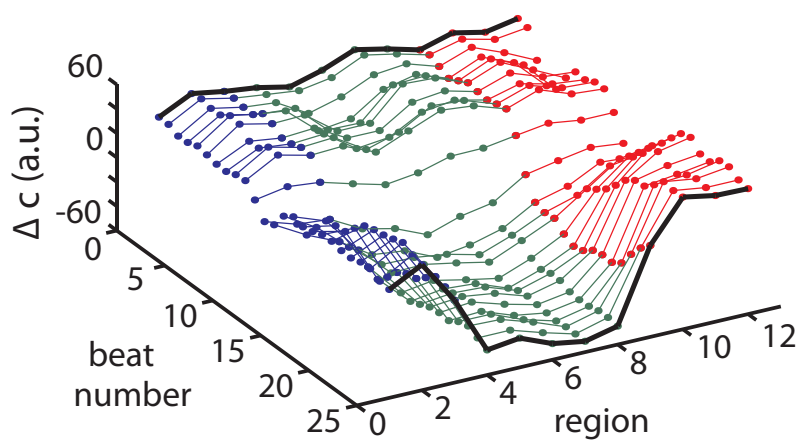

FIGURE 14 | Alternans control induces subcellular alternans in an isolated ventricular myocyte. (A) Alternans control causes a steady-state, period-2 APD (first black trace), and whole-cell $\mathrm{Ca}^{2+}$-alternans (second black trace) to transition to a period-1 rhythm. Concurrently, the spatially homogenous $\mathrm{Ca}^{2+}$-alternans transitions to a 2-node subcellular alternans. Blue, green, and red traces are the average fluorescence from the three regions diagrammed. (B) Recorded fluorescence frames at the time of maximum calcium concentration in two successive beats during initial control (1), during the transition (2), and at nearly period-1 control (3); beat pairs are marked by gray shaded regions in (A). (C) $\mathrm{Ca}^{2+}$-alternans magnitude along the length of the cell is plotted for the experiment shown in (A). For this panel, fluorescence data are binned into 12 adjacent regions perpendicular to the length of the cell and the average $\mathrm{Ca}^{2+}$-alternans magnitude $(\Delta c)$ is plotted for each region for the 25 beats shown (arbitrary fluorescence units), with colors corresponding to the regions diagrammed in (A). Fluorescence data from the extreme ends of the cell are excluded due to motion artifact. Experiments shown are from a cell paced at a cycle length of $300 \mathrm{~ms}$ (with alternans control). Adapted from Gaeta et al. (2009).
(Aistrup et al., 2009) or dynamically induced (Shiferaw and Karma, 2006; Gaeta et al., 2009, 2010; Xie and Weiss, 2009) heterogeneity in subcellular $\mathrm{Ca}^{2+}$-cycling characteristics.

Computational modeling has suggested that the heterogeneity in $\mathrm{Ca}^{2+}$ transients seen during subcellular alternans can result as a manifestation of fixed subcellular differences in the machinery of $\mathrm{Ca}^{2+}$-cycling. If different subcellular regions of a single myocyte have different $\mathrm{Ca}^{2+}$-release characteristics (e.g., degree of $\mathrm{Ca}^{2+}$ driven instability), changes in pacing protocol that reverse the phase of $\mathrm{Ca}^{2+}$ transient alternans can expose this heterogeneity by reversing the phase in some regions earlier than others (Aistrup et al., 2009). A similar effect is seen if such subcellular differences in $\mathrm{Ca}^{2+}$-release properties are instead induced dynamically by the propagation of intracellular $\mathrm{Ca}^{2+}$-waves (Xie and Weiss, 2009). An experimental study showed that if pacing is initiated during the propagation of a $\mathrm{Ca}^{2+}$-wave (induced by $\mathrm{Ca}^{2+}$-overload), the local gradients in refractoriness of SR $\mathrm{Ca}^{2+}$ release caused by the partially propagated $\mathrm{Ca}^{2+}$-wave led to a significant heterogeneity in the subsequent, pacing-induced $\mathrm{Ca}^{2+}$ transients. When rapid pacing was initiated as an intracellular $\mathrm{Ca}^{2+}$-wave propagated, a marked subcellular alternans pattern resulted (Figure 12; Xie and Weiss, 2009). This mechanism is analogous to a propagated ectopic activation inducing the transition from spatially concordant to spatially discordant alternans (described above).

Finally, a theoretical study suggested that a purely dynamical mechanism- a Turing-type, symmetry breaking instability- can induce subcellular alternans in rapidly paced, structurally homogeneous cells (Shiferaw and Karma, 2006). A canonical Turing ("diffusion-driven") instability is a mechanism by which a concentration gradient can be established from a nearly homogenous substrate due to the interaction of only two distinct, diffusing substances ("morphogens"; Turing, 1952). This occurs when an autocatalytic substance ("activating morphogen") gives rise to its own, more quickly diffusing inhibitor ("inhibitory morphogen"). A concentration gradient arises because local increases in activator concentration will grow (autocatalysis) but will also 
simultaneously inhibit increases in activator concentration away from this site (due to the production of the more quickly diffusing inhibitor; Gierer and Meinhardt, 1972).

An analogy was drawn between the amplitudes of $\mathrm{Ca}^{2+}$ alternans and APD-alternans and the concentrations of the activating and inhibitory morphogen in a canonical Turing instability (Shiferaw and Karma, 2006). By defining the " $\mathrm{Ca}^{2+}$-alternans amplitude" $(\Delta c)$ as the difference in peak calcium concentration of consecutive beats at each point along the length of a cell, subcellular alternans was able to be treated as the formation of a stable gradient in $\Delta c$ along the length of the cell (as seen in Figure 13). For example, if on two consecutive beats the left half of a myocyte experiences a small $\mathrm{Ca}^{2+}$-transient followed by a large transient concurrent with the right half having a large followed by a small transient, $\Delta c$ will be positive on the left and negative on the right.

Using a simplified coupled-map model, it was shown that such a gradient (subcellular alternans) will arise by a Turing instability given proper coupling between the AP and the $\mathrm{Ca}^{2+}$ transient. In particular, subcellular alternans was predicted to form by this mechanism during constant cycle length pacing of only those myocytes with negative $\mathrm{Ca}^{2+} \rightarrow \mathrm{V}_{\mathrm{m}}$ coupling (Shiferaw and Karma, 2006). The same mechanism was later shown theoretically to lead to subcellular alternans in cells with positive $\mathrm{Ca}^{2+} \rightarrow \mathrm{V}_{\mathrm{m}}$ coupling during pacing with a simple feedback control algorithm, "alternans control" (Gaeta et al., 2010). The latter prediction was confirmed by computational modeling and experiments using guinea pig ventricular myocytes (Figure 14; Gaeta et al., 2009, 2010). Notably, the cycle length perturbations of alternans control pacing are directly analogous to the changes in activation times seen distant from the pacing site during tissue-level spatially discordant alternans (due to alternating conduction velocity), even during pacing with a constant cycle length. In computational

\section{REFERENCES}

Aistrup, G. L., Kelly, J. E., Kapur, S., Kowalczyk, M., Sysman-Wolpin, I., Kadish, A. H., and Wasserstrom, J. A. (2006). Pacing-induced heterogeneities in intracellular $\mathrm{Ca} 2+$ signaling, cardiac alternans, and ventricular arrhythmias in intact rat heart. Circ. Res. 99, e65-e73.

Aistrup, G. L., Shiferaw, Y., Kapur, S., Kadish, A. H., and Wasserstrom, J. A. (2009). Mechanisms underlying the formation and dynamics of subcellular calcium alternans in the intact rat heart. Circ. Res. 104, 639-649.

Banville, I., Chattipakorn, N., and Gray, R. A. (2004). Restitution dynamics during pacing and arrhythmias in isolated pig hearts. J. Cardiovasc. Electrophysiol. 15, 455-463.

Banville, I., and Gray, R. A. (2002). Effect of action potential duration and conduction velocity restitution and their spatial dispersion on alternans and the stability of arrhythmias. J. Cardiovasc. Electrophysiol. 13, 1141-1149.
Bass, B. G. (1975). Restitution of the action potential in cat papillary muscle. Am. J. Physiol. 228, 1717-1724.

Bassani, J. W., Yuan, W., and Bers, D. M. (1995). Fractional sr ca release is regulated by trigger ca and sr ca content 268(Pt 1), C1313-C1319.

Bayer, J. D., Narayan, S. M., Lalani, G. G., and Trayanova, N. A. (2010). Ratedependent action potential alternans in human heart failure implicates abnormal intracellular calcium handling. Heart Rhythm 7, 1093-1101.

Bers, D. M. (2002). Cardiac excitationcontraction coupling. Nature 415, 198-205.

Bers, D. M. (2008). Calcium cycling and signaling in cardiac myocytes. Annu. Rev. Physiol. 70, 23-49.

Blatter, L. A. (2003). Local calcium gradients during excitation-contraction coupling and alternans in atrial myocytes. J. Physiol. (Lond.) 546, 19-31.

Brette, F., and Orchard, C. (2003). T-tubule function in mammalian in cardiac myocytes. Am. J. Physiol.

modeling experiments, subcellular alternans was indeed induced near the node of tissue-level spatially discordant alternans in a 1-dimensional fiber of simulated myocytes (Gaeta et al., 2009).

Regardless of pacing protocol, subcellular alternans is only predicted to occur if alternans is $\mathrm{Ca}^{2+}$-driven (Shiferaw and Karma, 2006; Gaeta et al., 2009, 2010), suggesting that in these experiments $\mathrm{Ca}^{2+}$ cycling instability was the primary mechanism of alternans. This also creates a possible utility for alternans control pacing as a test to indirectly identify the primary source of instability in different cell types and at different pacing cycle lengths (in which the presence or absence of resulting subcellular alternans indicates $\mathrm{Ca}^{2+}$-driven or $\mathrm{V}_{\mathrm{m}}$-driven instability, respectively; Gaeta et al., 2010).

\section{CONCLUSION AND FUTURE DIRECTIONS}

Cardiac alternans is a clinically important electrophysiological disturbance that leads to potentially fatal reentrant arrhythmias. Multiple mechanisms have been proposed to account for its occurrence at the tissue, cellular, and subcellular level. Alternans likely results from a rich interplay of structural and dynamical mechanisms, and an interdisciplinary approach is essential to its study. Several elegant interventions have been proposed to prevent or treat cardiac alternans, including pharmacologic (Verrier and Nieminen, 2010) or molecular (Livshitz and Rudy, 2007; Mahajan et al., 2008; Cutler et al., 2009) therapies aimed at quieting its underlying instability and electrical interventions that exploit its dynamics to halt its progression to potentially fatal arrhythmia (Christini et al., 2006; Krogh-Madsen et al., 2010; Kanu et al., 2011). More work is needed, however to establish the clinical utility of experimentally available options. An improved understanding of the mechanisms of cardiac alternans will hopefully facilitate the identification of clinical interventions for the prevention of sudden cardiac death.

cardiac myocytes. Circ. Res. 92, 1182-1192.

Cheng, H., and Lederer, W. J. (2008). Calcium sparks. Physiol. Rev. 88, 1491-1545.

Chinushi, M., Kozhevnikov, D., Caref, E. B., Restivo, M., and El-Sherif, N. (2003). Mechanism of discordant $\mathrm{t}$ wave alternans in the in vivo heart. J. Cardiovasc. Electrophysiol. 14, 632-638.

Chinushi, M., Restivo, M., Caref, E. B. and El-Sherif, N. (1998). Electrophysiological basis of arrhythmogenicity of qt/t alternans in the longqt syndrome: tridimensional analysis of the kinetics of cardiac repolarization. Circ. Res. 83, 614-628.

Christini, D. J., Riccio, M. L., Culianu, C. A., Fox, J. J., Karma, A., and Gilmour, R. F. (2006). Control of electrical alternans in canine cardiac Purkinje fibers. Phys. Rev. Lett. 96, 104101.

Chudin, E., Goldhaber, J., Garfinkel, A. Weiss, J., and Kogan, B. (1999). Intracellular $\mathrm{Ca}(2+)$ dynamics and the stability of ventricular tachycardia. Biophys. J. 77, 2930-2941.
Cordeiro, J. M., Malone, J. E., Diego, J. M. D., Scornik, F. S., Aistrup, G. L., Antzelevitch, C., and Wasserstrom, J. A. (2007). Cellular and subcellular alternans in the canine left ventricle. Am. J. Physiol. Heart Circ. Physiol. 293, H3506-H3516.

Cutler, M. J., and Rosenbaum, D. S. (2009). Explaining the clinical manifestations of $\mathrm{t}$ wave alternans in patients at risk for sudden cardiac death. Heart Rhythm 6(Suppl.), S22S28.

Cutler, M. J., Wan, X., Laurita, K. R., Hajjar, R. J., and Rosenbaum, D. S. (2009). Targeted serca2a gene expression identifies molecular mechanism and therapeutic target for arrhythmogenic cardiac alternans. Circ. Arrhythm. Electrophysiol. 2, 686-694.

Díaz, M. E., Eisner, D. A., and O’Neill, S. C. (2002). Depressed ryanodine receptor activity increases variability and duration of the systolic $\mathrm{Ca} 2+$ transient in rat ventricular myocytes. Circ. Res. 91, 585-593. 
Díaz, M. E., O’Neill, S. C., and Eisner, D. A. (2004). Sarcoplasmic reticulum calcium content fluctuation is the key to cardiac alternans. Circ. Res. 94, 650-656.

Diego, C. D., Pai, R. K., Dave, A. S., Lynch, A., Thu, M., Chen, F., Xie, LH., Weiss, J. N., and Valderrábano, M. (2008). Spatially discordant alternans in cardiomyocyte monolayers. Am. J. Physiol. Heart Circ. Physiol. 294, 1417-1425.

Echebarria, B., and Karma, A. (2007). Amplitude equation approach to spatiotemporal dynamics of cardiac alternans. Phys. Rev. E Stat. Nonlin. Soft Matter Phys. 76(Pt 1), 051911.

Euler, D. E. (1999). Cardiac alternans: mechanisms and pathophysiological significance. Cardiovasc. Res. 42 , 583-590.

Ferrari, G. M. D., Viola, M. C., D’Amato, E., Antolini, R., and Forti, S. (1995). Distinct patterns of calcium transients during early and delayed afterdepolarizations induced by isoproterenol in ventricular myocytes. Circulation 91, 2510-2515.

Fox, J. J., McHarg, J. L., and Gilmour, R. F. (2002a). Ionic mechanism of electrical alternans. Am. J. Physiol. Heart Circ. Physiol. 282, H516-H530.

Fox, J. J., Riccio, M. L., Hua, F., Bodenschatz, E., and Gilmour, R. F. (2002b). Spatiotemporal transition to conduction block in canine ventricle. Circ. Res. 90, 289-296.

Franz, M. R. (2003). The electrical restitution curve revisited: steep or flat slope-which is better? J. Cardiovasc. Electrophysiol. 14, S140-S147.

Fujiwara, K., Tanaka, H., Mani, H., Nakagami, T., and Takamatsu, T. (2008). Burst emergence of intracellular Ca2+waves evokes arrhythmogenic oscillatory depolarization via the $\mathrm{Na}+-\mathrm{Ca} 2+$ exchanger: simultaneous confocal recording of membrane potential and intracellular $\mathrm{Ca} 2+$ in the heart. Circ. Res. 103, 509-518.

Gaeta, S. A., Bub, G., Abbott, G. W., and Christini, D. J. (2009). Dynamical mechanism for subcellular alternans in cardiac myocytes. Circ. Res. 105, 335-342.

Gaeta, S. A., Krogh-Madsen, T., and Christini, D. J. (2010). Feedbackcontrol induced pattern formation in cardiac myocytes: a mathematical modeling study. J. Theor. Biol. 266, 408-418.

Garfinkel, A., Kim, Y. H., Voroshilovsky, O., Qu, Z., Kil, J. R., Lee, M. H., Karagueuzian, H. S., Weiss, J. N., and
Chen, P. S. (2000). Preventing ventricular fibrillation by flattening cardiac restitution. Proc. Natl. Acad. Sci. U.S.A. 97, 6061-6066.

Gierer, A., and Meinhardt, H. (1972). A theory of biological pattern formation. Kybernetik 12, 30-39.

Gilmour, R. F., Otani, N. F., and Watanabe, M. A. (1997). Memory and complex dynamics in cardiac Purkinje fibers. Am. J. Physiol. 272(Pt 2), H1826-H1832.

Goldhaber, J. I., Xie, L.-H., Duong, T., Motter, C., Khuu, K., and Weiss, J. N. (2005). Action potential duration restitution and alternans in rabbit ventricular myocytes: the key role of intracellular calcium cycling. Circ. Res. 96, 459-466.

Greenstein, J. L., and Winslow, R. L. (2002). An integrative model of the cardiac ventricular myocyte incorporating local control of $\mathrm{Ca} 2+$ release. Biophys. J. 83, 2918-2945.

Guevara, M., Ward, G., Shrier, A., and Glass, L. (1984). Electrical alternans and period doubling bifurcations. Comput. Cardiol. 167-170.

Hall, G., Bahar, S., and Gauthier, D. (1999). Prevalence of ratedependent behaviors in cardiac muscle. Phys. Rev. Lett. 82, 2995-2998.

Hüser, J., Wang, Y. G., Sheehan, K. A., Cifuentes, F., Lipsius, S. L., and Blatter, L. A. (2000). Functional coupling between glycolysis and excitationcontraction coupling underlies alternans in cat heart cells. J. Physiol. (Lond.) 524(Pt 3), 795-806.

Jordan, P. N., and Christini, D. J. (2007). Characterizing the contribution of voltage- and calciumdependent coupling to action potential stability: implications for repolarization alternans. Am. J. Physiol. Heart Circ. Physiol. 293, H2109H2118.

Kanu, U. B., Iravanian, S., Gilmour, R. F., and Christini, D. J. (2011). Control of action potential duration alternans in canine cardiac ventricular tissue. IEEE Trans. Biomed. Eng. 58, 894-904.

Kapur, S., Wasserstrom, J. A., Kelly, J. E., Kadish, A. H., and Aistrup, G. L. (2009). Acidosis and ischemia increase cellular $\mathrm{Ca} 2+$ transient alternans and repolarization alternans susceptibility in the intact rat heart. Am. J. Physiol. Heart Circ. Physiol. 296, H1491-H1512.

Karma, A., and Gilmour, R. (2007). Nonlinear dynamics of heart rhythm disorders. Phys. Today 60, 51.
Katz, A. (2005). Physiology of the Heart. Philadelphia: Lippincott Williams \& Wilkins.

Keurs, H. E. D. J. T., and Boyden, P. A. (2007). Calcium and arrhythmogenesis. Physiol. Rev. 87, 457-506.

Knot, H. J., Laher, I., Sobie, E. A., Guatimosim, S., Gomez-Viquez, L., Hartmann, H., Song, L.-S., Lederer, W. J., Graier, W. F., Malli, R., Frieden, M., and Petersen, O. H. (2005). Twenty years of calcium imaging: cell physiology to dye for. Mol. Interv. 5, 112-127.

Kockskämper, J., and Blatter, L. A. (2002). Subcellular Ca2+alternans represents a novel mechanism for the generation of arrhythmogenic $\mathrm{Ca} 2+$ waves in cat atrial myocytes. $J$. Physiol. (Lond.) 545(Pt 1), 65-79.

Koller, M. L., Maier, S. K. G., Gelzer, A. R., Bauer, W. R., Meesmann, M. and Gilmour, R. F. (2005). Altered dynamics of action potential restitution and alternans in humans with structural heart disease. Circulation 112, 1542-1548.

Koller, M. L., Riccio, M. L., and Gilmour, R. F. (1998). Dynamic restitution of action potential duration during electrical alternans and ventricular fibrillation. Am. J. Physiol. 275(Pt 2), H1635-H1642.

Krogh-Madsen, T., and Christini, D. J. (2007). Action potential duration dispersion and alternans in simulated heterogeneous cardiac tissue with a structural barrier. Biophys. $J$. 92, 1138-1149.

Krogh-Madsen, T., Karma, A., Riccio, M. L., Jordan, P. N., Christini, D. J., and Gilmour, R. F. (2010). Off-site control of repolarization alternans in cardiac fibers. Phys. Rev. E 81(Pt 1), 011915.

Livshitz, L. M., and Rudy, Y. (2007). Regulation of $\mathrm{Ca} 2+$ and electrical alternans in cardiac myocytes: role of camkii and repolarizing currents. Am. J. Physiol. Heart Circ. Physiol. 292, H2854-H2866.

Mahajan, A., Sato, D., Shiferaw, Y., Baher, A., Xie, L.-H., Peralta, R., Olcese, R., Garfinkel, A., Qu, Z., and Weiss, J. N. (2008). Modifying l-type calcium current kinetics: consequences for cardiac excitation and arrhythmia dynamics. Biophys. J. 94, 411-423.

Minamikawa, T., Cody, S. H., and Williams, D. A. (1997). In situ visualization of spontaneous calcium waves within perfused whole rat heart by confocal imaging. Am. J. Physiol. 272(Pt 2), H236-H243.

Miura, M., Ishide, N., Oda, H., Sakurai, M., Shinozaki, T., and Takishima, T.
(1993). Spatial features of calcium transients during early and delayed afterdepolarizations. Am. J. Physiol. 265(Pt 2), H439-H444.

Narayan, S. (2006). T-wave alternans and the susceptibility to ventricular arrhythmias. J. Am. Coll. Cardiol. 47, 269-281.

Narayan, S. M. (2008). T-wave alternans testing for ventricular arrhythmias. Prog. Cardiovasc. Dis. 51, 118-127.

Narayan, S. M., Bayer, J. D., Lalani, G., and Trayanova, N. A. (2008). Action potential dynamics explain arrhythmic vulnerability in human heart failure: a clinical and modeling study implicating abnormal calcium handling. J. Am. Coll. Cardiol. 52, 1782-1792.

Narayan, S. M., Franz, M. R., Clopton, P., Pruvot, E. J., and Krummen, D. E. (2011). Repolarization alternans reveals vulnerability to human atrial fibrillation. Circulation 123, 2922-2930.

Nieminen, T., and Verrier, R. L. (2010). Usefulness of $\mathrm{T}$-wave alternans in sudden death risk stratification and guiding medical therapy. Ann. Noninvasive Electrocardiol. 15, 276-288.

Nolasco, J. B., and Dahlen, R. W. (1968). A graphic method for the study of alternation in cardiac action potentials. J. Appl. Physiol. 25, 191-196.

O’Hara, T., Virág, L., Varró, A., and Rudy, Y. (2011). Simulation of the undiseased human cardiac ventricular action potential: model formulation and experimental validation. PLoS Comput. Biol. 7, e1002061. doi:10.1371/journal.pcbi.1002061

Orchard, C. H., Pásek, M., and Brette, F. (2009). The role of mammalian cardiac t-tubules in excitationcontraction coupling: experimental and computational approaches. Exp. Physiol. 94, 509-519.

Otani, N. F., and Gilmour, R. F. (1997). Memory models for the electrical properties of local cardiac systems. J. Theor. Biol. 187, 409-436.

Pastore, J. M., Girouard, S. D., Laurita, K. R., Akar, F. G., and Rosenbaum, D. S. (1999). Mechanism linking $\mathrm{t}$-wave alternans to the genesis of cardiac fibrillation. Circulation 99, 1385-1394.

Peterson, B. Z., DeMaria, C. D., Adelman, J. P., and Yue, D. T. (1999). Calmodulin is the $\mathrm{Ca} 2+$ sensor for $\mathrm{Ca} 2+$-dependent inactivation of $\mathrm{L}$ type calcium channels. Neuron 22, 549-558.

Picht, E., DeSantiago, J., Blatter, L. A., and Bers, D. M. (2006). Cardiac alternans do not rely on diastolic 
sarcoplasmic reticulum calcium content fluctuations. Circ. Res. 99, 740-748.

Pruvot, E. J., Katra, R. P., Rosenbaum, D. S., and Laurita, K. R. (2004). Role of calcium cycling versus restitution in the mechanism of repolarization alternans. Circ. Res. 94, 1083-1090.

Pruvot, E., and Rosenbaum, D. (2003). T-wave alternans for risk stratification and prevention of sudden cardiac death. Curr. Cardiol. Rep. 5, 350-357.

Qu, Z., Garfinkel, A., Chen, P. S., and Weiss, J. N. (2000). Mechanisms of discordant alternans and induction of reentry in simulated cardiac tissue. Circulation. 102, 1664-1670.

Qu, Z., and Weiss, J. N. (2007). The chicken or the egg? Voltage and calcium dynamics in the heart. Am. J. Physiol. Heart Circ. Physiol. 293, H2054-H2055.

Restrepo, J. G., Weiss, J. N., and Karma, A. (2008). Calsequestrinmediated mechanism for cellular calcium transient alternans. Biophys. J. 95, 3767-3789.

Riccio, M. L., Koller, M. L., and Gilmour, R. F. (1999). Electrical restitution and spatiotemporal organization during ventricular fibrillation. Circ. Res. 84, 955-963.

Rosenbaum, D. S., Jackson, L. E., Smith, J. M., Garan, H., Ruskin, J. N., and Cohen, R. J. (1994). Electrical alternans and vulnerability to ventricular arrhythmias. N. Engl. J. Med. 330, 235-241.

Rubenstein, D. S., and Lipsius, S. L. (1995). Premature beats elicit a phase reversal of mechanoelectrical alternans in cat ventricular myocytes. A possible mechanism for reentrant arrhythmias. Circulation 91, 201-214.

Salama, G. (2006). Arrhythmia genesis: aberrations of voltage or $\mathrm{Ca} 2+$ cycling? Heart Rhythm 3, 67-70.

Sato, D., Shiferaw, Y., Qu, Z., Garfinkel, A., Weiss, J. N., and Karma, A. (2007). Inferring the cellular origin of voltage and calcium alternans from the spatial scales of phase reversal during discordant alternans. Biophys. J. 92, L33-L35.

Shiferaw, Y., and Karma, A. (2006). Turing instability mediated by voltage and calcium diffusion in paced cardiac cells. Proc. Natl. Acad. Sci. U.S.A. 103, 5670-5675.

Shiferaw, Y., Qu, Z., Garfinkel, A., Karma, A., and Weiss, J. (2006). Nonlinear dynamics of paced cardiac cells. Ann. N. Y. Acad. Sci. 1080, 376-394.

Shiferaw, Y., Sato, D., and Karma, A. (2005). Coupled dynamics of voltage and calcium in paced cardiac cells. Phys. Rev. E Stat. Nonlin. Soft Matter Phys. 71(Pt 1), 021903.

Shiferaw, Y., Watanabe, M. A., Garfinkel, A., Weiss, J. N., and Karma, A. (2003). Model of intracellular calcium cycling in ventricular myocytes. Biophys. J. 85, 3666-3686.

Shimizu, W., and Antzelevitch, C. (1999). Cellular and ionic basis for $\mathrm{t}$-wave alternans under longqt conditions. Circulation 99, 1499-1507.

Sipido, K. R. (2006). Calcium overload, spontaneous calcium release, and ventricular arrhythmias. Heart Rhythm 3, 977-979.

Stern, M. D. (1992). Theory of excitation-contraction coupling in cardiac muscle. Biophys. J. 63, 497-517.

Stern, M. D., Song, L. S., Cheng, H., Sham, J. S., Yang, H. T., Boheler, K. R., and Ríos, E. (1999). Local control models of cardiac excitationcontraction coupling. A possible role for allosteric interactions between ryanodine receptors. J. Gen. Physiol. 113, 469-489.

Tolkacheva, E. G., Anumonwo, J. M. B., and Jalife, J. (2006). Action potential duration restitution portraits of mammalian ventricular myocytes: role of calcium current. Biophys. J. 91, 2735-2745.

Tolkacheva, E. G., Romeo, M. M., Guerraty, M., and Gauthier, D. J. (2004). Condition for alternans and its control in a two-dimensional mapping model of paced cardiac dynamics. Phys. Rev. E Stat. Nonlin. Soft Matter Phys. 69(Pt 1), 031904.

Turing, A. M. (1952). The chemical basis of morphogenesis. Philos. Trans. R. Soc. Lond. B Biol. Sci. 237, 37-72.

Venetucci, L. A., Trafford, A. W., O’Neill, S. C., and Eisner, D. A. (2008). The sarcoplasmic reticulum and arrhythmogenic calcium release. Cardiovasc. Res. 77, 285-292.

Verrier, R. L., Klingenheben, T., Malik, M., El-Sherif, N., Exner, D. V., Hohnloser, S. H., Ikeda, T., Martínez, J. P., Narayan, S. M., Nieminen, T., and Rosenbaum, D. S. (2011). Microvolt $\mathrm{T}$-wave alternans physiological basis, methods of measurement, and clinical utility-consensus guideline by International Society for Holter and Noninvasive Electrocardiology. J. Am. Coll. Cardiol. 58, 1309-1324.

Verrier, R. L., Kumar, K., and Nearing, B. D. (2009). Basis for sudden cardiac death prediction by $\mathrm{t}$-wave alternans from an integrative physiology perspective. Heart Rhythm 6, 416-422.

Verrier, R. L., and Nieminen, T. (2010). $\mathrm{T}$-wave alternans as a therapeutic marker for antiarrhythmic agents. $J$. Cardiovasc. Pharmacol. 55, 544-554.

Walker, M. L., and Rosenbaum, D. S. (2003). Repolarization alternans: implications for the mechanism and prevention of sudden cardiac death. Cardiovasc. Res. 57, 599-614.

Wan, X., Laurita, K. R., Pruvot, E. J., and Rosenbaum, D. S. (2005). Molecular correlates of repolarization alternans in cardiac myocytes. J. Mol. Cell. Cardiol. 39, 419-428.

Watanabe, M. A., Fenton, F. H., Evans, S. J., Hastings, H. M., and Karma, A. (2001). Mechanisms for discordant alternans. J. Cardiovasc. Electrophysiol. 12, 196-206.

Weiss, J. N., Karma, A., Shiferaw, Y., Chen, P.-S., Garfinkel, A., and Qu, Z (2006). From pulsus to pulseless: the saga of cardiac alternans. Circ. Res. 98, 1244-1253.

Willms, A. R., Baro, D. J., HarrisWarrick, R. M., and Guckenheimer, J. (1999). An improved parameter estimation method for hodgkinhuxley models. J. Comput. Neurosci. 6, 145-168.

Wilson, L., and Rosenbaum, D. (2007). Mechanisms of arrythmogenic cardiac alternans. Europace vi77-vi82.

Wu, R., and Patwardhan, A. (2004). Restitution of action potential duration during sequential changes in diastolic intervals shows multimodal behavior. Circ. Res. 94, 634-641.
Wu, R., and Patwardhan, A. (2006). Mechanism of repolarization alternans has restitution of action potential duration dependent and independent components. J. Cardiovasc. Electrophysiol. 17, 87-93.

Wu, T.-J., Lin, S.-F., Weiss, J. N., Ting, C.-T., and Chen, P.-S. (2002). Two types of ventricular fibrillation in isolated rabbit hearts: importance of excitability and action potential duration restitution. Circulation 106, 1859-1866.

Xie, L.-H., Sato, D., Garfinkel, A., Qu, Z., and Weiss, J. N. (2008). Intracellular ca alternans: coordinated regulation by sarcoplasmic reticulum release, uptake, and leak. Biophys. J. 95, 3100-3110.

Xie, L.-H., and Weiss, J. N. (2009). Arrhythmogenic consequences of intracellular calcium waves. Am. J. Physiol. Heart Circ. Physiol. 297, H997-H1002.

Zipes, D., and Jalife, J. (2004). Cardiac Electrophysiology: From Cell to Bedside. Philadelphia: Saunders.

Conflict of Interest Statement: The authors declare that the research was conducted in the absence of any commercial or financial relationships that could be construed as a potential conflict of interest.

Received: 22 February 2012; paper pending published: 23 March 2012; accepted: 05 May 2012; published online: 31 May 2012.

Citation: Gaeta SA and Christini DJ (2012) Non-linear dynamics of cardiac alternans: subcellular to tissue-level mechanisms of arrhythmia. Front. Physio. 3:157. doi: 10.3389/fphys.2012.00157

This article was submitted to Frontiers in Computational Physiology and Medicine, a specialty of Frontiers in Physiology. Copyright (c) 2012 Gaeta and Christini. This is an open-access article distributed under the terms of the Creative Commons Attribution Non Commercial License, which permits non-commercial use, distribution, and reproduction in other forums, provided the original authors and source are credited. 